\title{
Analysis and Evaluation of the Global Aerosol Optical Properties Simulated by an Online Aerosol-coupled Non-hydrostatic Icosahedral Atmospheric Model
}

\author{
DAI Tie ${ }^{* 1,2,3}$, SHI Guangyu ${ }^{1,3}$, and Teruyuki NAKAJIMA ${ }^{4}$ \\ ${ }^{1}$ State Key Laboratory of Numerical Modeling for Atmospheric Sciences and Geophysical Fluid Dynamics, \\ Institute of Atmospheric Physics, Chinese Academy of Sciences, Beijing 100029 \\ ${ }^{2}$ Key Laboratory for Aerosol-Cloud-Precipitation of China Meteorological Administration, \\ Nanjing University of Information Science and Technology, Nanjing 210044 \\ ${ }^{3}$ Collaborative Innovation Center on Forecast and Evaluation of Meteorological Disasters, \\ Nanjing University of Information Science and Technology, Nanjing 210044 \\ ${ }^{4}$ Atmosphere and Ocean Research Institute, University of Tokyo, Kashiwa, Japan
}

(Received 25 August 2014; revised 22 October 2014; accepted 15 November 2014)

\begin{abstract}
Aerosol optical properties are simulated using the Spectral Radiation Transport Model for Aerosol Species (SPRINTARS) coupled with the Non-hydrostatic ICosahedral Atmospheric Model (NICAM). The 3-year global mean all-sky aerosol optical thickness (AOT) at $550 \mathrm{~nm}$, the Ångström Exponent (AE) based on AOTs at 440 and $870 \mathrm{~nm}$, and the single scattering albedo (SSA) at $550 \mathrm{~nm}$ are estimated at 0.123, 0.657 and 0.944, respectively. For each aerosol species, the mean AOT is within the range of the AeroCom models. Both the modeled all-sky and clear-sky results are compared with observations from the Moderate Resolution Imaging Spectroradiometer (MODIS) and the Aerosol Robotic Network (AERONET). The simulated spatiotemporal distributions of all-sky AOTs can generally reproduce the MODIS retrievals, and the correlation and model skill can be slightly improved using the clear-sky results over most land regions. The differences between clear-sky and all-sky AOTs are larger over polluted regions. Compared with observations from AERONET, the modeled and observed all-sky AOTs and AEs are generally in reasonable agreement, whereas the SSA variation is not well captured. Although the spatiotemporal distributions of all-sky and clear-sky results are similar, the clear-sky results are generally better correlated with the observations. The clear-sky AOT and SSA are generally lower than the all-sky results, especially in those regions where the aerosol chemical composition is contributed to mostly by sulfate aerosol. The modeled clear-sky AE is larger than the all-sky AE over those regions dominated by hydrophilic aerosol, while the opposite is found over regions dominated by hydrophobic aerosol.
\end{abstract}

Key words: aerosol optical properties, non-hydrostatic icosahedral atmospheric model, Moderate Resolution Imaging Spectroradiometer, Aerosol Robotic Network

Citation: Dai, T., G. Y. Shi, and T. Nakajima, 2015: Analysis and evaluation of the global aerosol optical properties simulated by an online aerosol-coupled non-hydrostatic icosahedral atmospheric model. Adv. Atmos. Sci., 32(6), 743-758, doi: $10.1007 / \mathrm{s} 00376-014-4098-\mathrm{z}$.

\section{Introduction}

Atmospheric aerosols have great impacts on the environment, human health, and the earth's climate (Twomey, 1974; Kampa and Castanas, 2008; Zhang et al., 2012a). Currently, the effects of aerosol on climate (especially the interactions among aerosols, radiation, and clouds) are one of the largest uncertainties in model simulations and climate change assessment (Lohmann et al., 2010). To properly quantify aerosol

\footnotetext{
* Corresponding author: DAI Tie

Email: daitie@mail.iap.ac.cn
}

effects on the climate system, we need to accurately estimate aerosol optical properties such as aerosol optical thickness (AOT), Ångström exponent (AE) and single scattering albedo (SSA) with models (Goto et al., 2012).

The optical properties of aerosols are determined not only by the aerosol amount, but also by physical and optical parameters such as aerosol size distribution, the mixing state of particles, hygroscopic growth, and refractive indices, especially in absorbing particles such as black carbon (BC) and dust. These parameters are either prescribed empirically or calculated explicitly in global climate aerosol models (Kinne et al., 2006; Textor et al., 2007; Peng et al., 2012; Zhang et 
al., 2012b; Mann et al., 2014), and the uncertainties of such parameters can induce significant differences in the simulated aerosol optical properties (Goto et al., 2011b). Aerosol modeling also suffers from poorly known aerosol life cycles and emission inventories (Textor et al., 2006, 2007). Thus, the aerosol model has to be evaluated against observations before we can place confidence in such a model (Takemura et al., 2002a; Prados et al., 2007; Chin et al., 2009; Su and Toon, 2011; Ridley et al., 2012).

Evaluations of simulated aerosol optical fields in climate models have been performed in many previous studies, and resulting knowledge of aerosol processes has generally improved (Chin et al., 2002; Kinne et al., 2003; Lee and Adams, 2010; Chin et al., 2014). This makes modeled AOTs generally comparable to observations. However, the pathway to making such a match is less well constrained, and uncertainties associated with aerosol and aerosol-cloud interaction modeling are still large (Textor et al., 2006; Lee et al., 2013). Model results and observations are often compared in an inconsistent manner (Chin et al., 2002). Observations of aerosol optical properties are generally retrieved only under cloud-free conditions, whereas model results used for comparison are generally calculated under all-sky conditions. The effect of such an inconsistent comparison on modeled AOT evaluation has been studied recently (Colarco et al., 2010). The indication is that sampling model output consistently with satellite AOT retrievals is a more appropriate methodology to making aerosol model evaluations. Separating the modeled aerosol optical properties with a new aerosol-coupled version of the Non-hydrostatic ICosahedral Atmospheric Model (NICAM) into all-sky and clear-sky properties, we present a model to observation comparison of the AOT, AE and SSA using both the modeled all-sky and clear-sky results in the present study. In the next section, the model setup and observation data used are described. The general model performances are shown in section 3.1. The model results are further evaluated by comparing them with MODIS and AERONET retrievals in sections 3.2 and 3.3, respectively. The paper closes with a conclusion in section 4 .

\section{Model description and observation data}

\subsection{Model description}

The Non-hydrostatic ICosahedral Atmospheric Model (NICAM) is designed to perform cloud-resolving simulations by directly calculating deep convection and mesoscale circulations, which play key roles not only in tropical circulation but also the global circulation of the atmosphere (Satoh et al., 2008). The model has been used for several types of global cloud-resolving experiments with horizontal resolutions up to $3.5 \mathrm{~km}$ (Satoh et al., 2008), including a realistic simulation of the Madden-Julian Oscillation (Miura et al., 2007). These studies demonstrate that NICAM reproduces the detailed features of global cloud and precipitation fields. The Spectral Radiation Transport Model for Aerosol Species (SPRINTARS) is a global three-dimensional aerosol transport-radiation model, described fully in Takemura et al. (2000; 2002a; 2009) and Goto et al. (2011a). In the aerosolcoupled version of NICAM (Suzuki et al., 2008), which is referred to as NICAM+SPRINTARS, the mass mixing ratios of the main tropospheric aerosols, i.e., carbonaceous aerosols (BC and organic carbon), sulfate, soil dust, sea salt, and the precursor gases of sulfate, are predicted with the transport processes including advection, convection, diffusion, gravitational settling, and wet and dry deposition. The advection scheme of NICAM has desirable requirements for tracer transport simulations: mass conservation, monotonicity, and efficiency (Niwa et al., 2011b). These facts encourage us to use NICAM+SPRINTARS as an aerosol transport model.

The present study requires a long-term model integration to include the aerosol seasonal variation. This makes it too expensive to perform the model simulation with cloudresolving resolutions, which directly simulate the cloud microphysics using a one-moment (Tomita, 2008) or twomoment bulk scheme (Seiki and Nakajima, 2014; Seiki et al., 2014) for several days only (Miura et al., 2007; Suzuki et al., 2008). NICAM can also be run at coarser resolutions (Niwa et al., 2011a; Dai et al., 2014a), using the prognostic Arakawa-Schubert cumulus convection scheme (Arakawa and Schubert, 1974) and large-scale condensation scheme (Le Trent and Li, 1991) for cloud parameterization. NICAM is still advantageous when run at coarser resolutions, especially for transport simulations, because of the conservation of mass. Thus, we perform the model simulation with a coarse horizontal resolution of $224 \mathrm{~km}$ and 40 vertical layers and the model top located at $40 \mathrm{~km}$ for four years (2005-08). The first year is used for spinup. The column cloud fraction is calculated with the commonly used maximum-random overlap method (Geleyn and Hollingsworth, 1979). The other model physics, such as the minimal advanced treatments of surface interaction and runoff (MATSIRO) land surface scheme (Takata et al., 2003), the two-stream $k$-distribution radiation scheme (Nakajima et al., 2000; Sekiguchi and Nakajima, 2008), and the level 2 vertical turbulence closure scheme (Mellor and Yamada, 1974) are identical to those used in the cloud-resolving resolutions. National Centers for Environmental Prediction (NCEP) Final (FNL) operational global tropospheric analyses are used for the initial and boundary conditions.

The emission inventories of $\mathrm{BC}$ are based on the Global Emissions Inventory Activity (GEIA) database (Cooke and Wilson, 1996), as monthly means without yearly variation, with the exception of the fossil fuel consumption emission. The latter is based on yearly mean data taken from the AeroCom phase-II dataset (Diehl et al., 2012). Assuming different emission ratios of $\mathrm{OC}$ to $\mathrm{BC}$ according to the burning conditions (Takemura et al., 2000; Takemura et al., 2002a), the OC emission flux is calculated by the model itself. The inventory of sulfate aerosol precursor $\left(\mathrm{SO}_{2}\right)$ is also taken from the AeroCom phase-II dataset. The dust and sea salt emission fluxes are parameterized as in Takemura et al. (2009). The oxidant concentrations, such as ozone and hydroxyl radical, which are required to calculate sulfate chemistry (Takemura et al., 
2000), are given by a global chemical transport model (Sudo et al., 2002). For proper simulation of the aerosol distribution, the modeled wind, water vapor, and temperature fields are nudged to the NCEP FNL analysis data with a time-scale of six hours.

The modeled AOT, AE and SSA are calculated in the same way as Dai et al. (2014a) by using the newly proposed optical parameters. Hygroscopic growths for sulfate, organic carbon, and sea salt are parameterized as a function of relative humidity to consider the aerosol water uptake (Takemura et al., 2002a). The relative humidity is calculated identically for clear-sky and cloud-sky grids based on the ClausiusClapeyron equation with grid mean values (i.e., grid mean specific humidity and temperature). The model integral time step is 20 minutes, and the aerosol optical properties are calculated at each integral time step but archived at every 3 hours. The modeled daily mean aerosol optical properties are simple means of the eight instantaneous snapshots per day. To examine the effect of cloud on the evaluation of the model results, we separate the simulated monthly mean aerosol optical properties into clear-sky and all-sky properties. We sample the modeled daily aerosol optical properties to the daily cloud-free observations and calculate the modeled clear-sky monthly aerosol optical properties by averaging the sampled daily results, whereas the all-sky ones are calculated without any conditional sampling.

\subsection{The MODIS products}

The Moderate Resolution Imaging Spectroradiometer (MODIS) is a key instrument onboard the NASA earth observing system satellites (Salomonson et al., 1989; Barnes et al., 1998). It has the ability to monitor the spatiotemporal variation of the global aerosol and cloud fields over both ocean and land with several well-calibrated spectral channels (King et al., 1992; Kaufman et al., 1997; Tanré et al., 1997). To eliminate the strong solar reflectance by cloud, MODIS Level 2 AOT retrieval at a $10 \times 10 \mathrm{~km}^{2}$ resolution considers only the best cloud-free pixels using a sophisticated cloud screen as a preprocessing step (Ackerman et al., 1998; Martins et al., 2002; Remer et al., 2005). The Level 2 AOT is further aggregated to Level 3 gridded global product at a $1^{\circ} \times 1^{\circ}$ resolution (King et al., 2003; Remer and Kaufman, 2006). In the present study, the MODIS Collection 5.1 daily Level 3 products of AOT at $550 \mathrm{~nm}$ and cloud fraction from both the Terra and Aqua satellites are used, which can be downloaded freely from NASA's innovative data analysis and visualization system (http://disc.sci.gsfc.nasa.gov/giovanni/overview/ index.html) (Acker and Leptoukh, 2007).

\subsection{AERONET dataset}

The Aerosol Robotic Network (AERONET) provides the largest dataset of global aerosol optical properties derived from ground-based remote sensing using sun/skyradiometers (Holben et al., 1998; Dubovik et al., 2000). In the present study, the daily average AERONET Level 2.0 almucantar inversion products are used for comparison (http:// aeronet.gsfc.nasa.gov/cgi-bin/combined_data_access_inv).
The AERONET AOTs and SSAs at both 440 and $675 \mathrm{~nm}$ are interpolated to compare with the modeled results at 550 $\mathrm{nm}$ under the assumption that the AOTs are proportional to wavelength on a logarithmic scale. The AE used for comparison is determined from the AOTs at 440 and $870 \mathrm{~nm}$.

\section{Results}

\subsection{Global aerosol distribution with NICAM}

Figure 1 shows the three-year averaged global distribution of simulated AOT under all-sky conditions at the wavelength of $550 \mathrm{~nm}$ for individual aerosol components and its relative contribution to the total AOT. The sulfate and dust aerosols are located mainly in the Northern Hemisphere, whereas the carbonaceous aerosols and sea salt are located mainly in the Southern Hemisphere. High AOT values $(>0.2)$ for sulfate aerosol are found in eastern Asia and Europe because of the high emission of the sulfate aerosol precursor $\mathrm{SO}_{2}$ from fossil fuel consumption. Carbonaceous aerosols originating from biomass burning are prominent in central and southern Africa, Southeast Asia, and South America, with AOT values generally higher than 0.2. The maximum value of dust AOT $(>0.3)$ is seen over the Sahara Desert area, and the dust with high AOT emitted from the deserts of East Asia is also simulated well (Wang et al., 2008; Bi et al., 2011). High sea salt AOT ( $>0.1)$ located near $60^{\circ} \mathrm{S}$ directly reflects the high emission rates due to the strong surface wind. In terms of the global 3-year means, soil dust aerosol has the largest AOT (0.035), followed by sulfate aerosol (0.032), carbonaceous aerosol (0.030), and sea salt (0.026). As shown in Table 1, the mean AOTs of NICAM for both aerosol species and the total are all within the ranges of the 20 aerosol models that participated in the AeroCom exercise (Kinne et al., 2006). For dust aerosol, sulfate aerosol and the total, the mean AOTs are close to $(\sim 10 \%)$ the AeroCom means. For carbonaceous aerosol and sea salt, the mean AOTs are $30.4 \%$ higher and $18.7 \%$ lower than the AeroCom means, respectively. Sulfate aerosol usually contributes more than $40 \%$ to the total AOT over major pollution regions, such as East Asia, Europe, and eastern America. On the other hand, carbonaceous aerosols contribute most $(>60 \%)$ to the total AOT over biomass burning regions. Sea salt aerosol contributes the most to the AOT over oceans, except the paths of the Asian aerosol transpacific transport and the Sahara dust transatlantic transport. Dust aerosol contributes over $60 \%$ to the total AOT over the desert source and outflow regions.

$\mathrm{AE}$ indicates the wavelength dependence of AOT, which is used commonly to infer the aerosol particle size distribution and chemical composition (Chung et al., 2012; Logan et al., 2013). Small aerosol particles (i.e. sulfate and carbonaceous) have strong wavelength dependence and thus large AE. SSA governs the strength of aerosol in absorption (Dubovik et al., 2000). The AE and SSA both have spatial distributions related to the aerosol chemical composition (figure not shown for brevity). Large AEs $(>1.0)$ in biomass burning and pollution regions are found because 

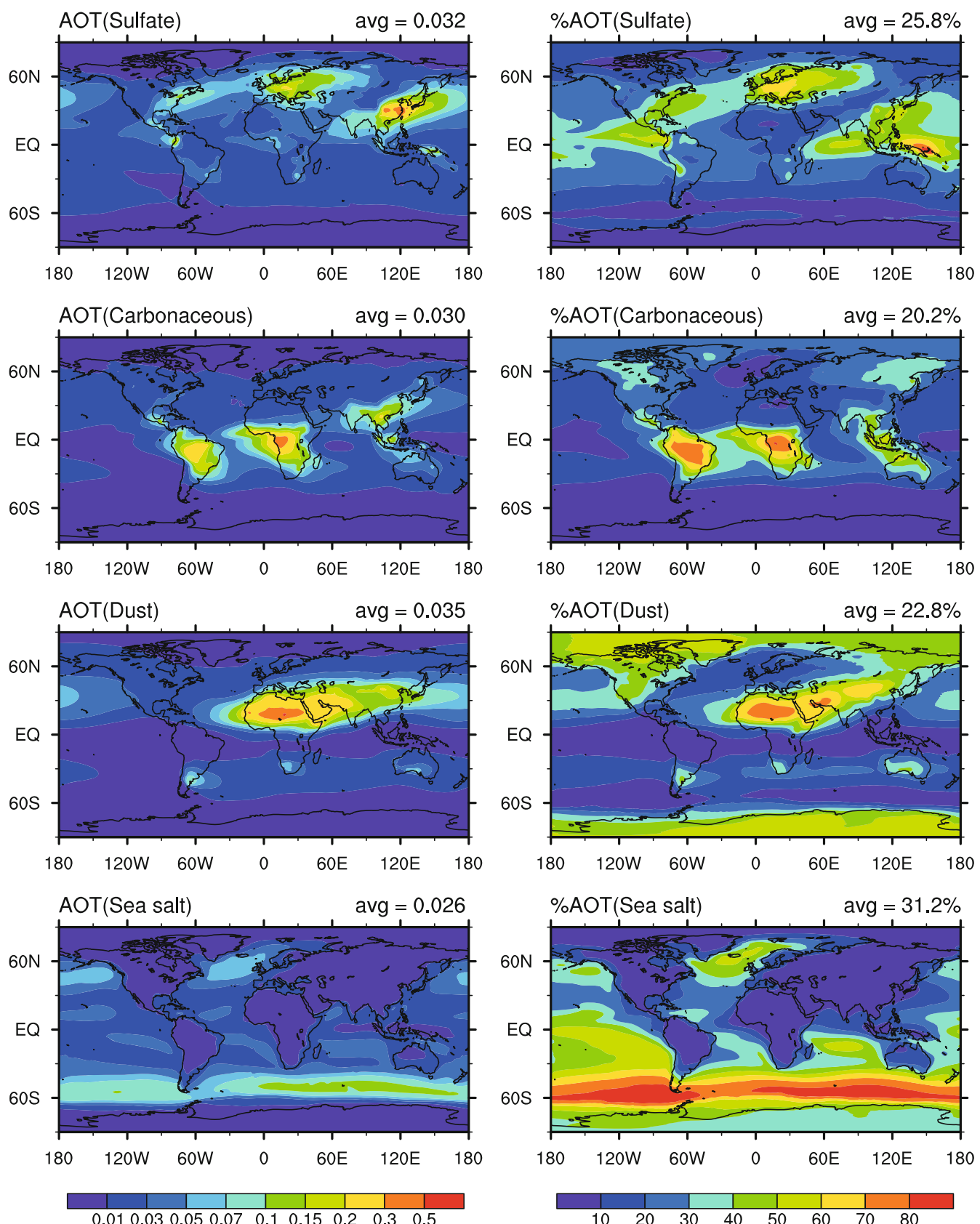

Fig. 1. NICAM-simulated 3-year averaged all-sky AOTs at $550 \mathrm{~nm}$ (left column) for individual aerosol components and its contribution to the total AOT (right column).

Table 1. Globally and annually averaged AOTs at $550 \mathrm{~nm}$ with NICAM+SPRINTARS, the AeroCom means, and the AeroCom ranges.

\begin{tabular}{cccccc}
\hline Models & Dust & Sulfate & Carbonaceous & Sea salt & Total \\
\hline NICAM & 0.035 & 0.032 & 0.030 & 0.026 & 0.123 \\
AeroCom means & 0.031 & 0.035 & 0.023 & 0.032 & 0.122 \\
AeroCom ranges & $0.009-0.054$ & $0.015-0.051$ & $0.008-0.046$ & $0.003-0.067$ & $0.06-0.151$ \\
\hline
\end{tabular}

small aerosol particles (sulfate and carbonaceous) are dominant in such areas. Small AEs $(<0.6)$ are seen in the dust or sea salt aerosol predominant regions because the aerosol particles are large. Dust and carbonaceous aerosols make the
SSAs as small as $0.86-0.90$ because of their strong absorption properties. Over the remote ocean, especially in the Southern Hemisphere, the SSAs are around 1.0, as non-absorbing sea salt aerosol dominates. 


\subsection{Comparisons with MODIS retrievals}

The modeled climatology of all-sky AOTs at $550 \mathrm{~nm}$, the corresponding MODIS retrievals, and the discrepancies for January, April, July, and October are shown in Fig. 2. The simulated AOTs can reproduce the general characteristics of aerosol distribution as observed by MODIS. AOTs are commonly higher over the Saharan, Arabian and East Asian regions, and the seasonal variation of AOT with higher values in April and July is mostly regulated by the larger dust aerosol emissions (Yang et al., 2008; Ridley et al., 2012). Although the model tends to overestimate the AOTs over biomass burning regions in July, the strong seasonal cycles of the biomass burning in the Congo and Amazon basins are captured. The transpacific transport of the aerosol plume from East Asia to North America (Takemura et al., 2002b; Logan et al., 2010) is evident from both the model and satellite results. The discrepancies reveal the model tends to underestimate the transatlantic transport of the Saharan Desert dust and overestimate the transpacific transport of the East Asian aerosols, except during the summer season.

To investigate the effect of cloud cover on AOT simulation, the modeled climatology of all-sky and clear-sky AOTs are compared in Fig. 3. Distinct differences are found over the regions of East Asia, Europe, and eastern America, where aerosols are mostly from pollution sources. The clear-sky AOTs are generally lower than the all-sky AOTs, especially in January. The maximum absolute and relative differences over -0.3 and $-30 \%$, respectively, are found over eastern China in January. To clarify the reason for such maximal differences, the modeled and MODIS-retrieved cloud fraction are also compared. The MODIS cloud fraction is highest over eastern China in January (figure not shown for brevity), and this will cause more higher modeled AOTs to be masked out for the climatology of clear-sky AOTs because the sulfate aerosol is mostly formed in clouds and the hygroscopic growth is more effective in higher humidity regions near the clouds (Takemura et al., 2000; Goto et al., 2011a). Meanwhile, we find there is a clear correlation between the simulated cloud fraction distributions and MODIS results, although the model tends to underestimate the cloud fraction over North America, Eurasia, and the western coasts of the main continents, as in many other models (Le Trent and Li, 1991). Detailed verification of the modeled cloud structures is beyond the scope of this study. Over the tropical and subtropical ocean regions, the clear-sky AOTs are generally

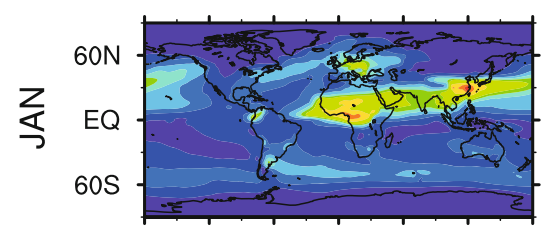

180 120W60W $0 \quad 60$ E 120E 180
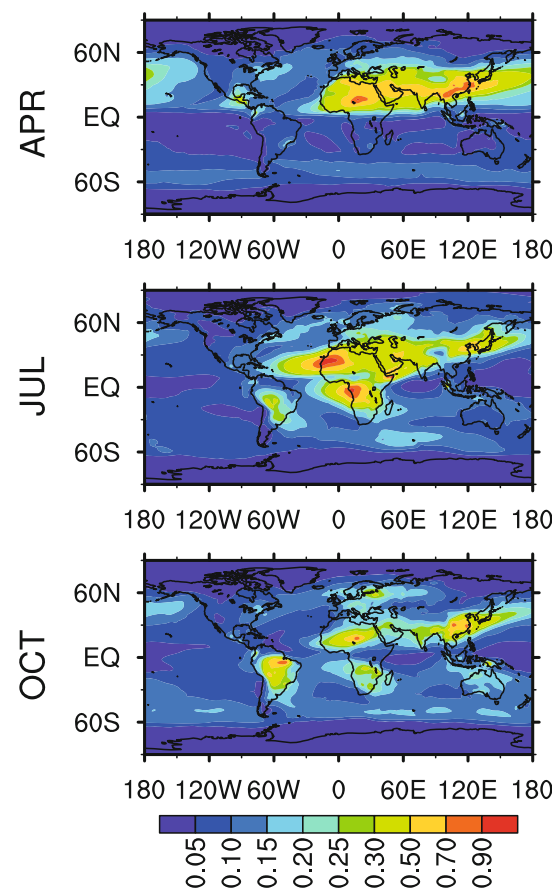

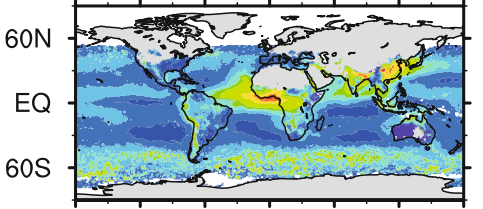

180 120W60W $0 \quad 60$ E 120E 180

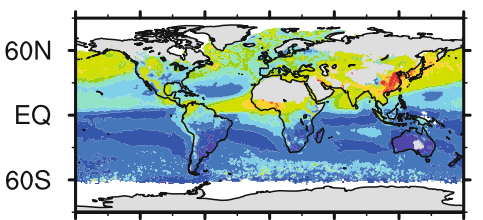

180 120W60W $0 \quad 60$ E 120E 180
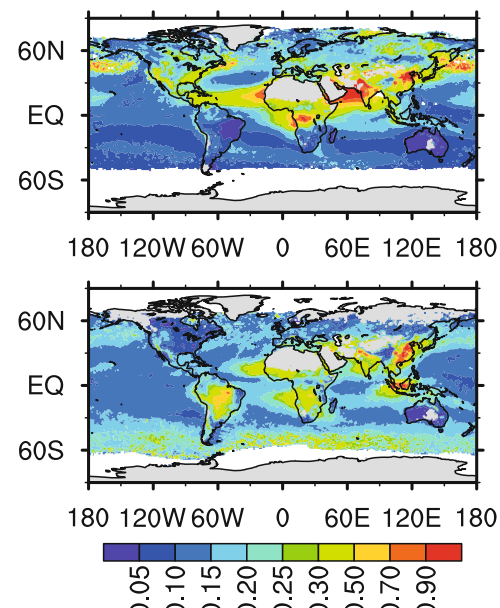

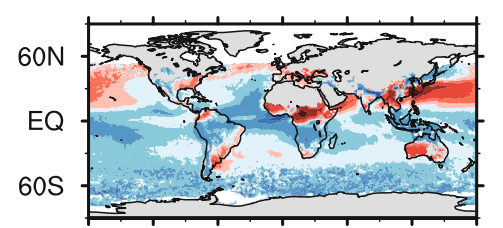

180 120W60W $0 \quad 60$ E 120E 180

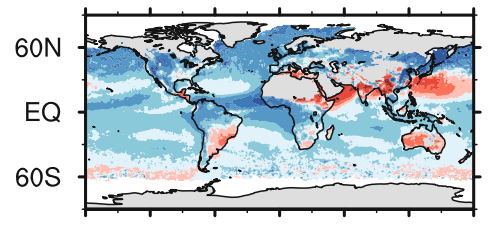

180 120W60W $0 \quad 60$ E 120 E 180
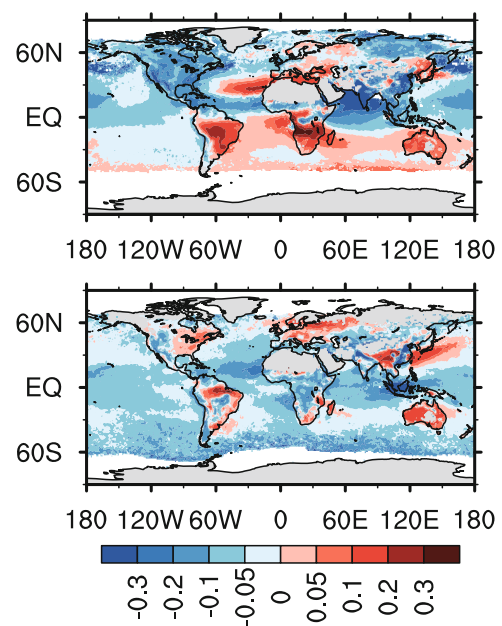

Fig. 2. Modeled all-sky AOTs at $550 \mathrm{~nm}$ (left column), the corresponding MODIS-retrieved AOTs (middle column), and the differences between the modeled and MODIS-retrieved AOTs (right column) in January (top row), April (2nd row), July (3rd row), and October (bottom row) averaged over the 3-year period from 2006 to 2008. 

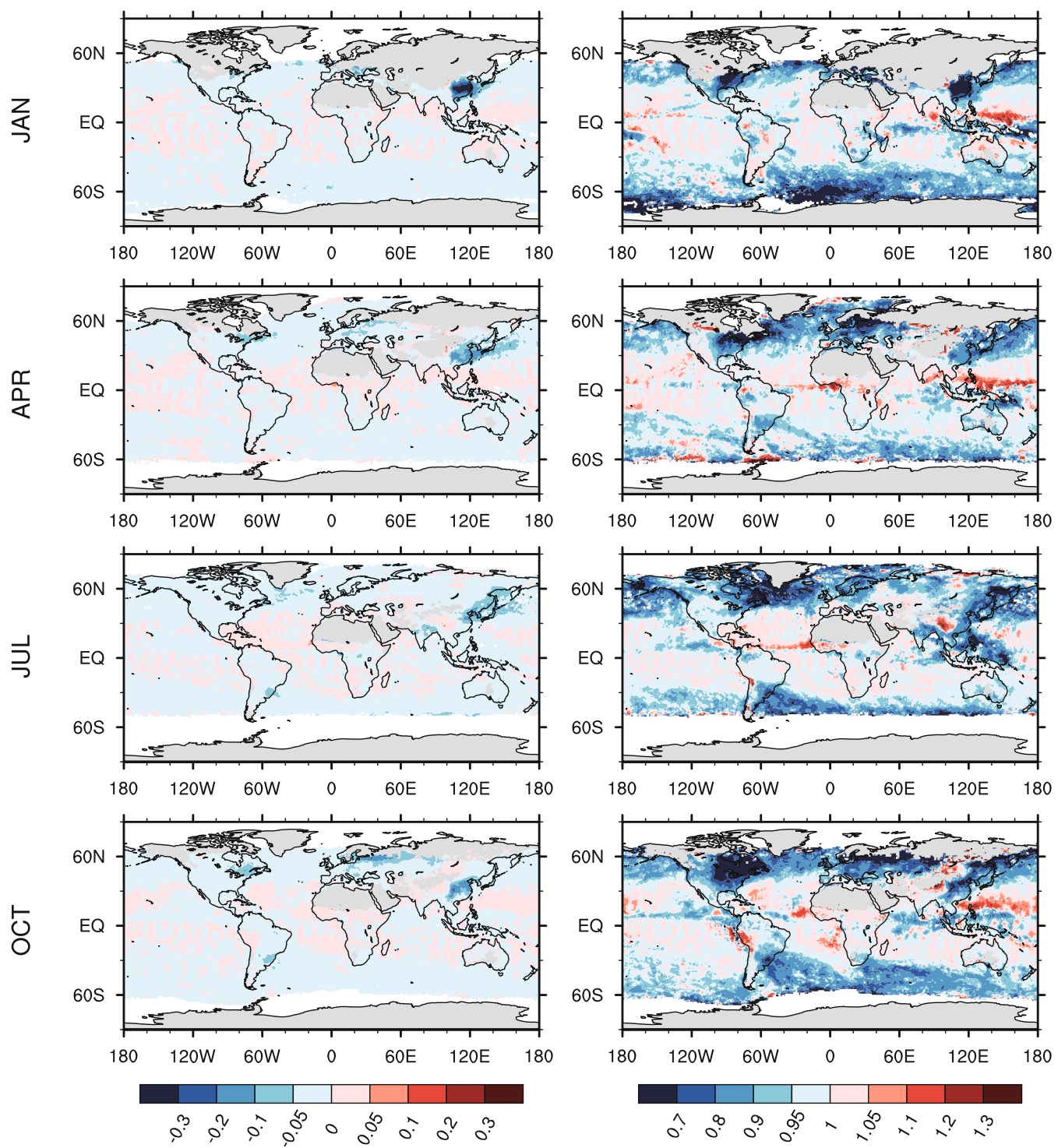

Fig. 3. Absolute (left column) and relative (right column) differences of the modeled all-sky and clear-sky AOTs in January (top row), April (2nd row), July (3rd row), and October (bottom row) averaged over the 3-year period from 2006 to 2008. The absolute difference is defined as the clear-sky AOT minus the all-sky AOT. The relative difference is defined as the ratio of the clear-sky AOT to the all-sky AOT.

slightly higher $(<0.05)$ than the all-sky ones, and this could induce some high relative differences where the AOTs are also small, such as over the tropical Pacific. The clear-sky AOTs are generally slightly lower $(<-0.05)$ than the all-sky AOTs over the Southern Ocean near $60^{\circ} \mathrm{S}$, where the cloud fraction and sea salt aerosol are generally higher. This indicates that the sea salt AOT enhancement by hygroscopic growth is larger than the decrement caused by the wet deposition under high-cloud or high-humidity conditions, and the large AOT under high cloud fraction conditions may be masked out to calculate the climatology of clear-sky AOT.

To evaluate the evolution of the modeled AOTs quantitatively, we compare the modeled AOTs over land and over ocean with MODIS retrievals separately. The global land area is divided into seven regions according to the aerosol sources and their geographical locations, similar to Chin et al. (2009): North America (NAM), Europe (EUR), Asia (ASA), northern Africa and the Middle East (NAF), South America (SAM), southern Africa (SAF), and Australia/New Zealand/tropical western Pacific countries (AUS) (Fig. 4a). Figures 4b-i show comparisons of the regional and global monthly mean modeled AOT over land under both clear-sky and all-sky conditions with the MODIS retrievals. The statistical parameters, including the correlation coefficient $(R)$, bias, and model skill are given in Table 2. The model skill depends on both $R$ and the standard deviations of the observed and modeled results:

$$
\frac{4(1+R)}{\left(\sigma_{\mathrm{f}}+1 / \sigma_{\mathrm{f}}\right)^{2}\left(1+R_{0}\right)},
$$

where $\sigma_{\mathrm{f}}$ is the ratio of the standard deviation of the model to 
Table 2. Summary of the statistical parameters for the comparisons shown in Fig. 4.

\begin{tabular}{|c|c|c|c|c|c|c|c|}
\hline \multirow[b]{2}{*}{ Region } & \multirow[b]{2}{*}{ MODIS Mean } & \multicolumn{2}{|c|}{$R$} & \multicolumn{2}{|c|}{ Bias } & \multicolumn{2}{|c|}{ Model Skill } \\
\hline & & All-sky & Clear-sky & All-sky & Clear-sky & All-sky & Clear-sky \\
\hline NAM & 0.171 & 0.416 & 0.589 & -0.082 & -0.096 & 0.217 & 0.255 \\
\hline SAM & 0.181 & 0.656 & 0.657 & -0.017 & -0.024 & 0.804 & 0.816 \\
\hline EUR & 0.196 & 0.512 & 0.589 & -0.013 & -0.040 & 0.663 & 0.772 \\
\hline NAF & 0.348 & 0.586 & 0.573 & -0.043 & -0.049 & 0.748 & 0.754 \\
\hline SAF & 0.215 & 0.742 & 0.740 & -0.015 & -0.019 & 0.580 & 0.585 \\
\hline ASA & 0.335 & 0.753 & 0.801 & -0.086 & -0.111 & 0.875 & 0.900 \\
\hline AUS & 0.113 & 0.354 & 0.367 & -0.012 & -0.015 & 0.662 & 0.664 \\
\hline Global land & 0.234 & 0.641 & 0.690 & -0.049 & -0.062 & 0.818 & 0.841 \\
\hline
\end{tabular}
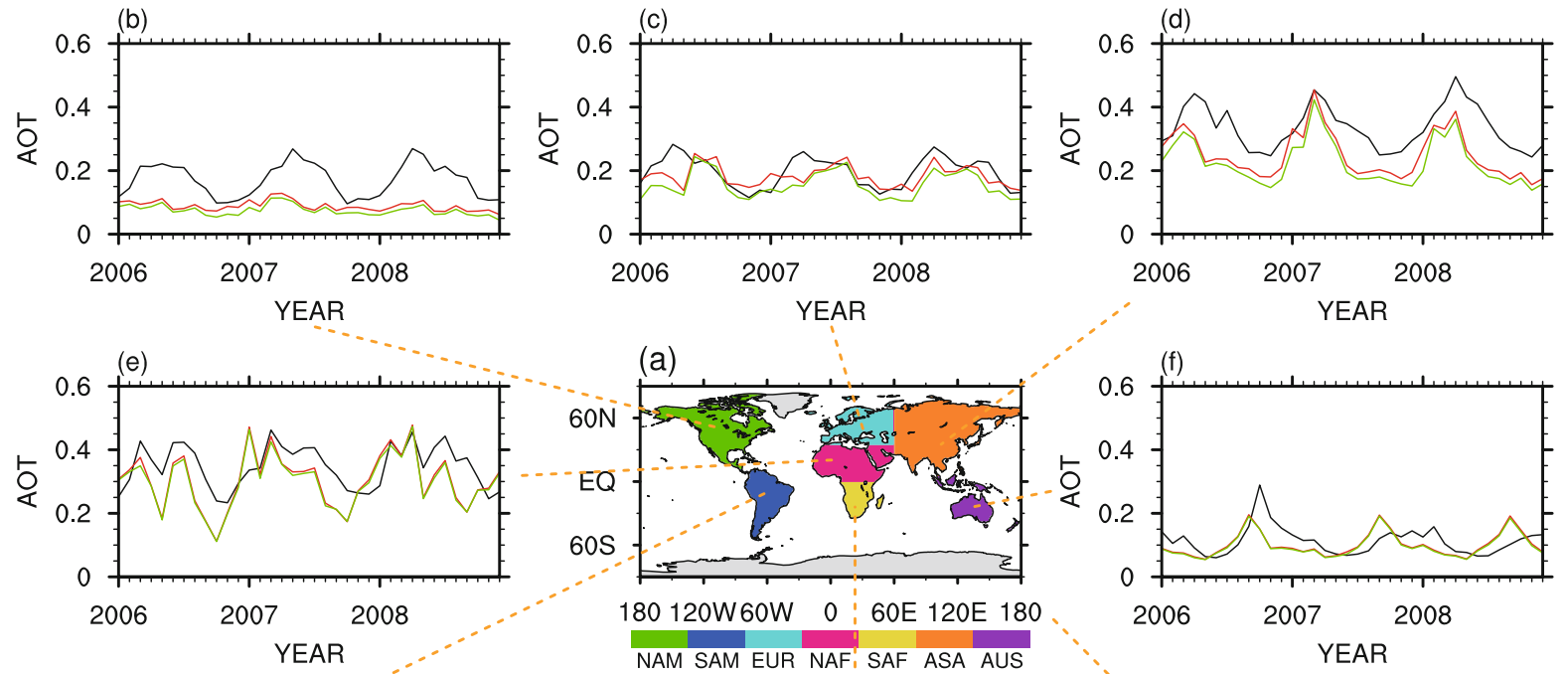

(a)
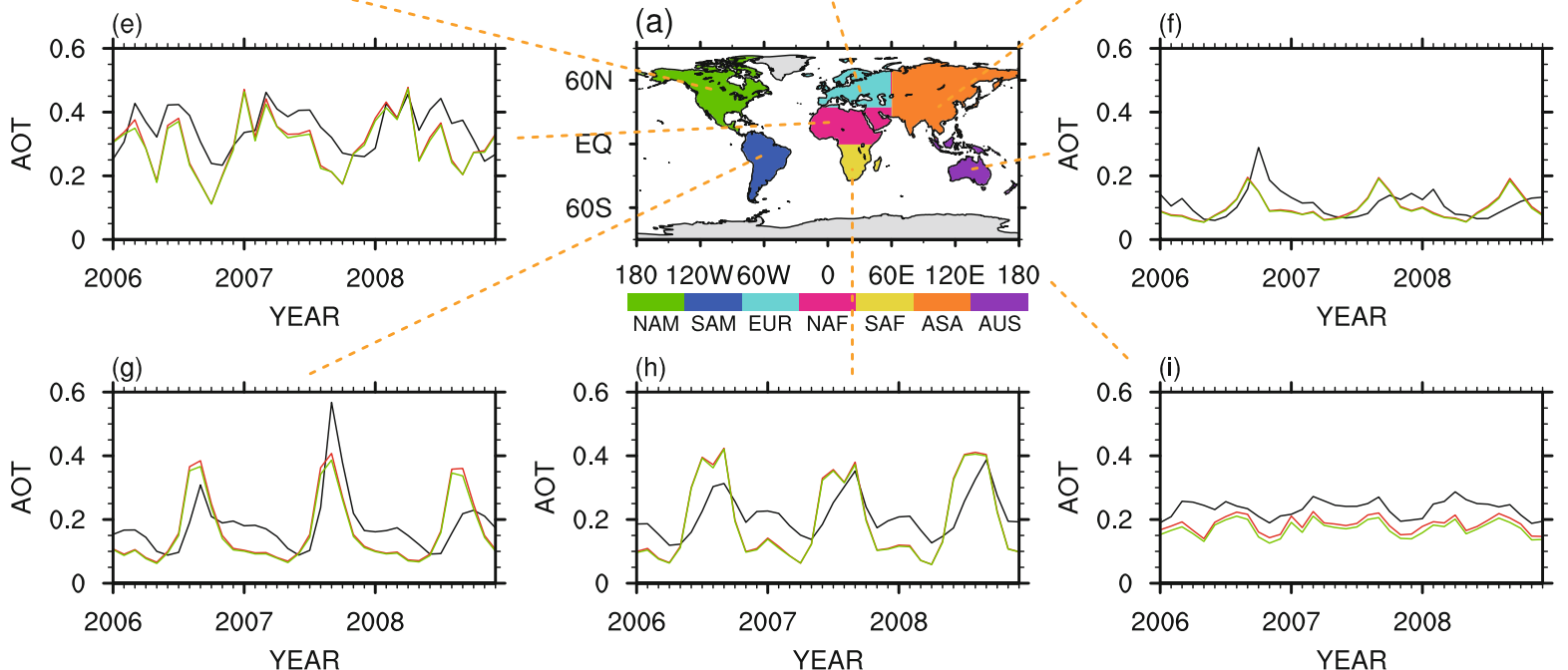

Fig. 4. (a) Definition of the different land regions used in this study. The surrounding panels compare the variation of modeled monthly all-sky AOT (red line), clear-sky AOT (green line), and MODIS AOT (black line) over (b-h) the different regions and (i) the global land area.

that of the observation, and $R_{0}$ is the maximum attainable $R$, which is set to 1 (Taylor, 2001; Chin et al., 2009). Note that the regional monthly mean AOT under all-sky conditions is calculated using only the grid values where monthly mean MODIS AOTs are available. It is clear that the modeled all-sky and clear-sky AOTs can both reproduce the monthly AOT variability as observed by MODIS, except over NAM where the modeled AOT variability is too small compared to MODIS results. Although the model tends to underestimate the AOTs over all regions, and the clear-sky AOTs further enlarge the underestimations, the clear-sky AOTs are better correlated with the observed AOTs. This indicates that the aerosol variations are better simulated using the modeled clear-sky results, and this is further verified by the incre- ments of the model skill using the clear-sky AOTs over all regions. The global ocean is also divided into seven regions, as shown in Fig. 5a: northern Atlantic (NA), northern Pacific (NP), tropical northern Atlantic (TA), southern Pacific (SP), southern Atlantic (SA), Indian Ocean (IO), and Southern Ocean (SO). Similar comparisons over the ocean as over land are shown in Figs. 5b-i, and the statistical parameters are given in Table 3. The model shows higher skill in simulating the monthly AOT variations over the downwind regions of the main land aerosol sources, such as the outflows of dust aerosol from the Sahara Desert (TA), mixed aerosols from East Asia (NP), and biomass burning aerosols from South America (SA). The differences between clear-sky and all-sky AOTs are generally ignorable, except over the NA and SO 
Table 3. Summary of the statistical parameters for the comparisons shown in Fig. 5.

\begin{tabular}{|c|c|c|c|c|c|c|c|}
\hline \multirow[b]{2}{*}{ Region } & \multirow[b]{2}{*}{ MODIS Mean } & \multicolumn{2}{|c|}{$R$} & \multicolumn{2}{|c|}{ Bias } & \multicolumn{2}{|c|}{ Model Skill } \\
\hline & & All-sky & Clear-sky & All-sky & Clear-sky & All-sky & Clear-sky \\
\hline NA & 0.184 & 0.412 & 0.339 & -0.061 & -0.073 & 0.417 & 0.331 \\
\hline NP & 0.193 & 0.459 & 0.434 & -0.040 & -0.050 & 0.723 & 0.705 \\
\hline TA & 0.252 & 0.798 & 0.798 & -0.108 & -0.108 & 0.898 & 0.897 \\
\hline SP & 0.123 & 0.392 & 0.411 & -0.061 & -0.062 & 0.679 & 0.693 \\
\hline SA & 0.183 & 0.835 & 0.833 & -0.049 & -0.051 & 0.893 & 0.897 \\
\hline $\mathrm{IO}$ & 0.194 & 0.398 & 0.389 & -0.069 & -0.071 & 0.595 & 0.572 \\
\hline SO & 0.147 & 0.550 & 0.602 & -0.046 & -0.055 & 0.418 & 0.345 \\
\hline Global ocean & 0.171 & 0.497 & 0.520 & -0.061 & -0.067 & 0.693 & 0.725 \\
\hline
\end{tabular}
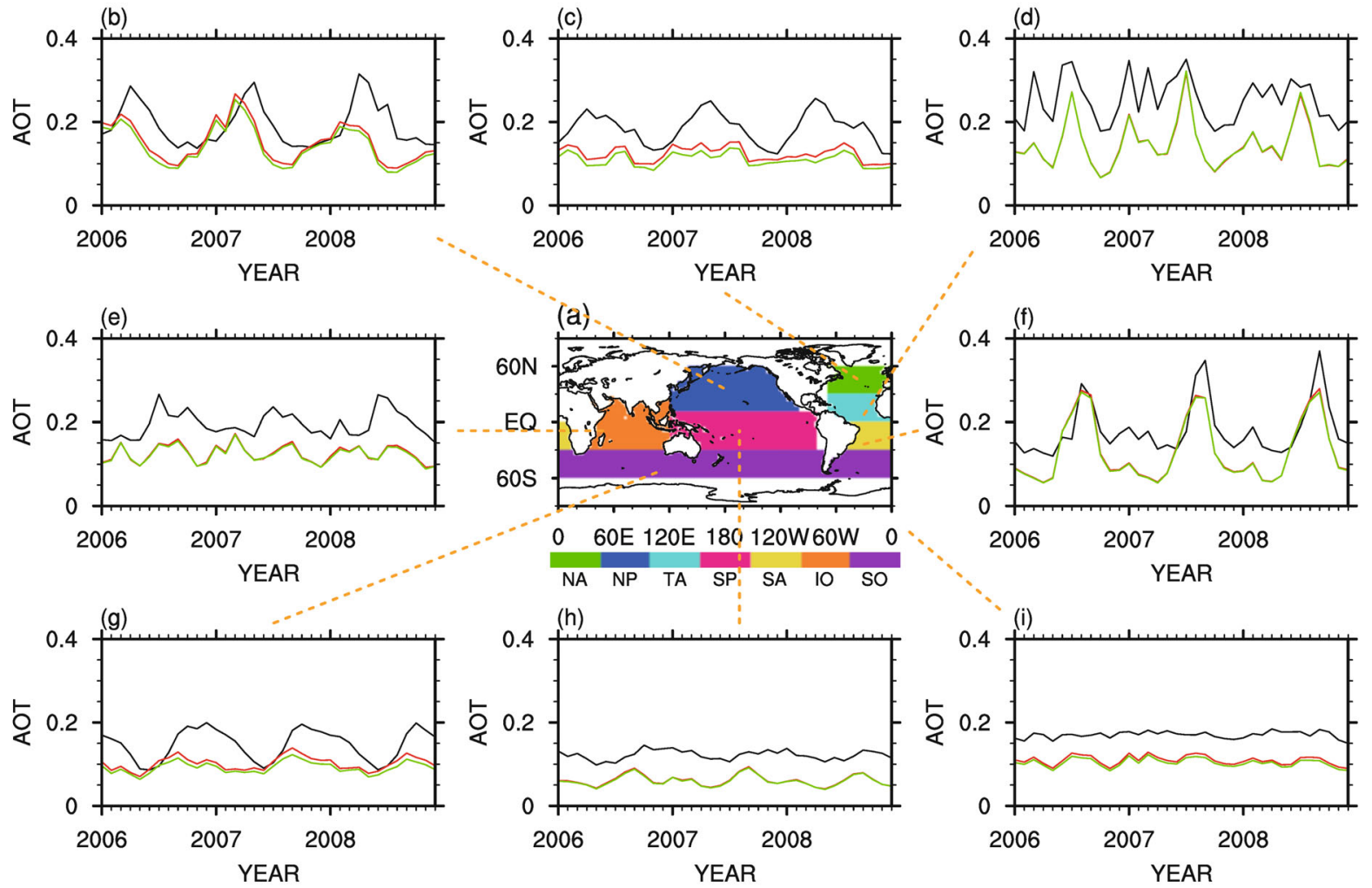

Fig. 5. (a) Definition of the different ocean regions used in this study. The surrounding panels show comparisons of the variation of modeled monthly all-sky AOT (red line), clear-sky AOT (green line), and MODIS AOT (black line) over (b-h) the different regions and (i) the global ocean.

regions. Although the $R$ values of the clear-sky AOTs with observations are higher over the SO region, the increment of underestimation using clear-sky AOTs further induces the decrement of the model skill. On the basis of the global ocean, the clear-sky AOT is better correlated with the observation and slightly increases the model skill.

Figure 6a shows the 3-year mean differences of the modeled daily AOTs and the MODIS retrievals over land as a function of MODIS cloud fraction. During the comparison, the modeled AOTs are sampled to the observations for the regional mean. The differences are clearly dependent on the cloud fraction over all regions. The model tends to overestimate the AOTs over the AUS, SAF, SAM, and NAF regions under low cloud fraction conditions, whereas underestima- tions are found under high cloud fraction conditions. In these regions, aerosols are mostly from dust and biomass burning sources. The cloud only affects the wet deposition of these aerosols. Insufficient wet deposition under low cloud fraction conditions induces the overestimation of the AOT. The model underestimates the AOTs under all cloud conditions over the ASA, EUR, and NAM regions. In these regions, aerosols are dominated by sulfate. The cloud affects both the formation and the wet deposition of sulfate. Although the wet deposition is small when the cloud cover is low, the insufficient formation of sulfate could cause the underestimation of AOT. It is interesting that the AOT underestimation increases with the cloud fraction over all regions. As shown in Fig. 6b, the MODIS AOT increases with the cloud fraction 
(a)

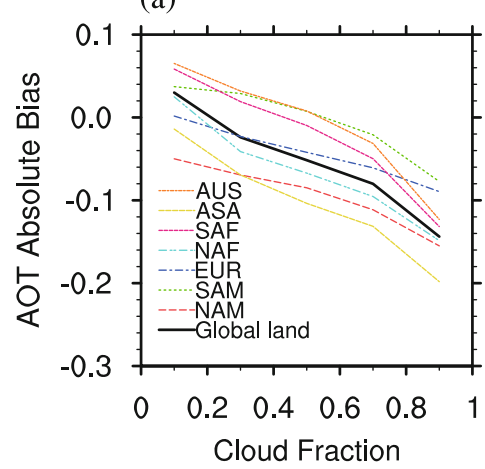

(d)

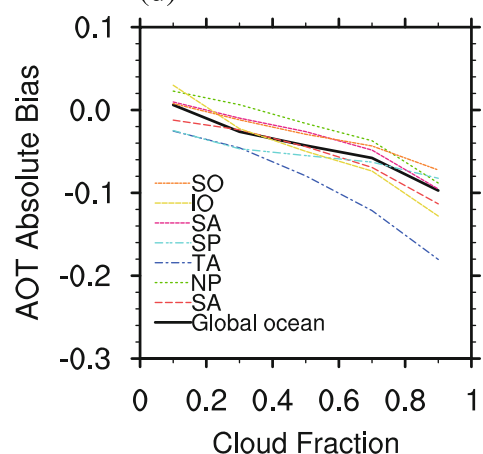

(b)

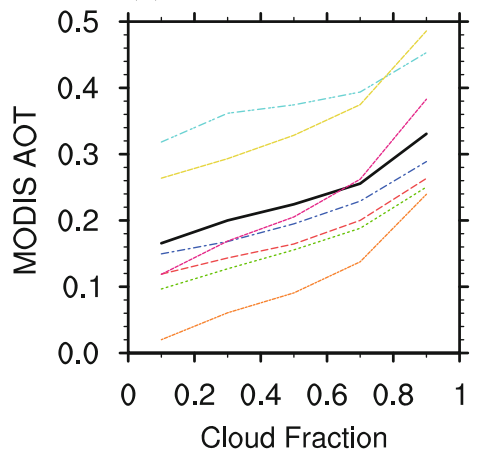

(e)

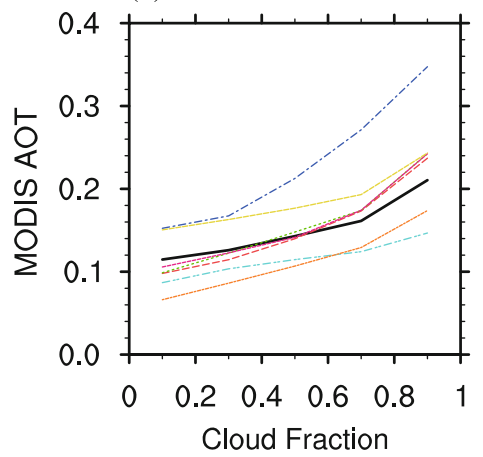

(c)

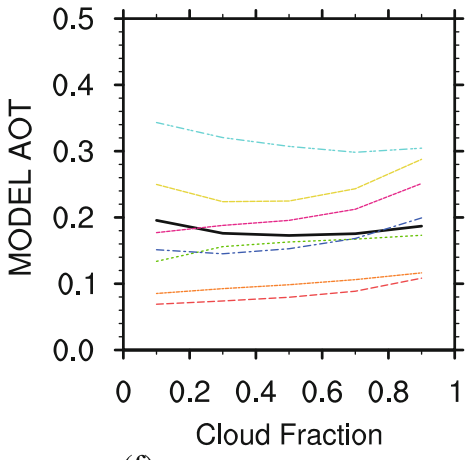

(f)

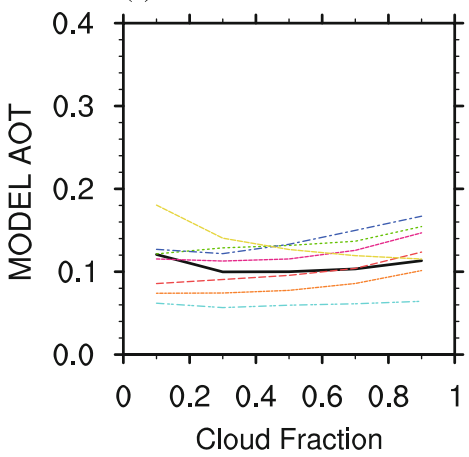

Fig. 6. Mean differences of the modeled and MODIS-retrieved daily AOTs over the 3-year period for varying cloud fraction over (a) land and (d) ocean, the mean MODIS-retrieved AOTs for varying cloud fraction over (b) land and (e) ocean, and the mean modeled AOTs with varying cloud fraction over (c) land and (f) ocean.

over all regions, and such enhancement can be well explained as the aerosol hygroscopic growth in the humid environment surrounding clouds (Chand et al., 2012). As shown in Fig. $6 \mathrm{c}$, the model can generally reproduce AOT enhancements with the cloud fraction except over the NAF region; however, the slopes of enhancements are much smaller than in the MODIS retrievals. This indicates that the model may underestimate the effect of aerosol hygroscopic growth, while MODIS may overestimate the AOT under higher cloud fraction caused by the unscreened cloud particles with AOT uncertainties of about $5 \%-15 \%$ (Remer et al., 2005). In our model, the consideration of hydrophobic dust aerosol induces the decrement of the AOT with cloud fraction over the NAF region. Similar results are also found over the ocean regions, as shown in Figs. 6d-f.

\subsection{Comparisons with AERONET observations}

AERONET simultaneously retrieves AOT, AE, and SSA (Dubovik and King, 2000; Dubovik et al., 2000), and this makes more aerosol characteristics available to constrain model performances. The modeled monthly and 3-year mean AOT and SSA at $550 \mathrm{~nm}$ and the AE based on AOTs at 440 and $870 \mathrm{~nm}$ are compared with the AERONET retrievals. The monthly and 3-year mean AERONET-retrieved optical values are derived from the daily mean values. There are in total 148 AERONET sites that have more than 120 daily mean retrievals during the period 2006 to 2008. The locations of these AERONET sites are shown in Fig. 7a, and the
AERONET sites are also further classified into seven world regions. The regional mean observed aerosol optical properties are calculated using the available observations at the AERONET sites located over each region, and the regional mean modeled results are calculated similarly to the observed ones by interpolating the model results to the corresponding AREONET sites.

Figures $7 \mathrm{~b}-\mathrm{i}$ show inter-comparisons of the modeled allsky, clear-sky, and the retrieved monthly mean AOT variations on the basis of regional and global means, and the statistical parameters are given in Table 4. Similar comparisons for the AE and SSA are shown in Figs. 8 and 9, and the statistical parameters are summarized in Tables 5 and 6, respectively. Over the NAM and EUR regions, where aerosols are mostly from pollution sources, the observed AOTs show clear seasonal variation, which is reproduced better by using the clear-sky AOTs than the all-sky AOTs, although the clear-sky AOTs are more biased than the all-sky AOTs over the NAM region. Such an influence is not so obvious with respect to the comparisons of the AE and SSA values. The monthly variations of AE and SSA are not clear, except that the AEs are slightly lower during the spring season in the NAM region. The latter could be caused by the frequent occurrence of Asian dust transpacific transport in the spring season (Logan et al., 2010). Over the biomass burning regions of SAM and SAF, the observed monthly variations of AOTs and AEs with peaks during biomass burning periods are also slightly improved with higher model skill by using 
Table 4. Summary of the statistical parameters for the comparisons shown in Fig. 7.

\begin{tabular}{|c|c|c|c|c|c|c|c|}
\hline \multirow[b]{2}{*}{ Region } & \multirow[b]{2}{*}{ MODIS Mean } & \multicolumn{2}{|c|}{$R$} & \multicolumn{2}{|c|}{ Bias } & \multicolumn{2}{|c|}{ Model Skill } \\
\hline & & All-sky & Clear-sky & All-sky & Clear-sky & All-sky & Clear-sky \\
\hline NAM & 0.110 & 0.244 & 0.538 & -0.005 & -0.029 & 0.348 & 0.425 \\
\hline SAM & 0.158 & 0.744 & 0.765 & 0.048 & 0.032 & 0.870 & 0.882 \\
\hline EUR & 0.154 & 0.313 & 0.422 & 0.022 & -0.001 & 0.656 & 0.708 \\
\hline NAF & 0.374 & 0.779 & 0.783 & -0.070 & -0.062 & 0.872 & 0.856 \\
\hline SAF & 0.134 & 0.665 & 0.659 & 0.025 & 0.020 & 0.691 & 0.703 \\
\hline ASA & 0.436 & 0.666 & 0.658 & -0.076 & -0.137 & 0.816 & 0.826 \\
\hline AUS & 0.060 & 0.357 & 0.401 & 0.037 & 0.030 & 0.677 & 0.695 \\
\hline All & 0.210 & 0.737 & 0.760 & -0.010 & -0.035 & 0.824 & 0.863 \\
\hline
\end{tabular}
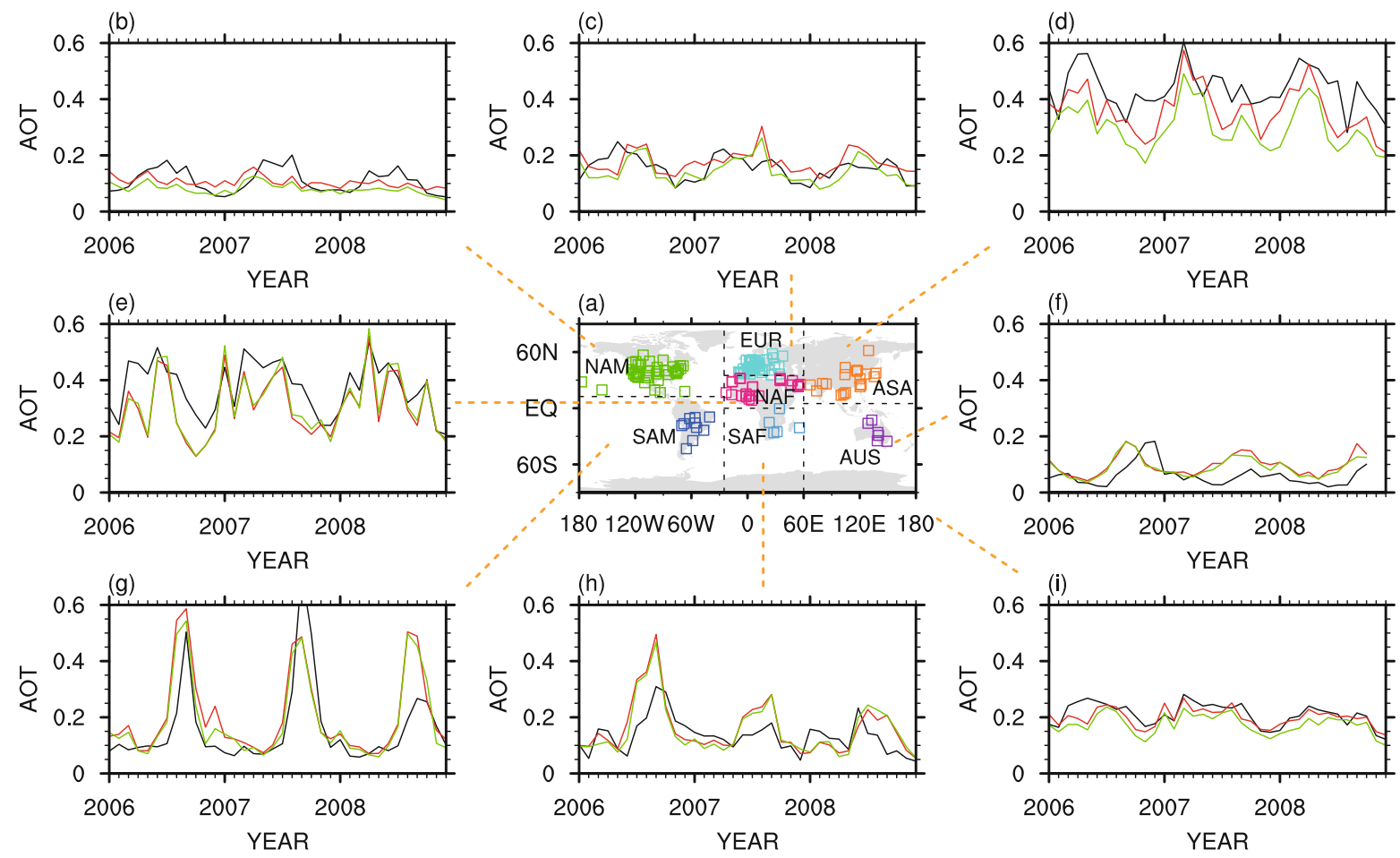

Fig. 7. (a) Locations of the AERONET sites used in this study and the seven regions these sites are further divided into. the surrounding panels show inter-comparisons between the modeled all-sky (red line), clear-sky (green line) and AERONET-retrieved (black line) monthly mean AOT variations at $550 \mathrm{~nm}$ on the basis of the (b-h) regional mean and (i) global mean.

clear-sky results. The retrieved SSAs with lower values during the biomass burning season over the SAF region are also better simulated by the clear-sky results, although the bias is slightly higher than based on the all-sky results. Over the NAF and AUS regions, where aerosols are mostly from dust sources, except those perturbed by biomass burning, the observed AOT, AE, and SSA variations are also better reproduced by the clear-sky results with higher $R$. In the ASA region, where the aerosol composition is more complicated, although the biases of AOT, AE and SSA are enlarged with the clear-sky results, the variations are better reproduced by the clear-sky results with higher $R$ and model skill for both $\mathrm{AOT}$ and $\mathrm{AE}$.

Figure 10 shows an inter-comparison of the modeled allsky, clear-sky, and observed 3-year mean of AOT, AE and
SSA over all the available AERONET sites. As shown in Figs. 10a-c, on a global basis, the all-sky and clear-sky AOTs, AEs and SSAs are significantly correlated with $R$ values of $0.963,0.985$, and 0.950 , respectively, indicating similar horizontal distributions of clear-sky and all-sky results. The 3-year mean all-sky AOT, AE, and SSA are 0.203, 0.895 , and 0.916 , respectively, which are $0.022,0.019$, and 0.008 higher than the clear-sky values. The clear-sky AOT is generally lower than the all-sky AOT, except over the dustdominant regions. The clear-sky AE is generally larger than the all-sky $\mathrm{AE}$ when the $\mathrm{AE}$ value is high $(>1.1)$, whereas the clear-sky $\mathrm{AE}$ is lower than the all-sky $\mathrm{AE}$ when the $\mathrm{AE}$ value is low $(<0.6)$. The high $\mathrm{AE}$ value indicates that the AOT is contributed to mostly by the sulfate and/or carbonaceous aerosols. These aerosol radii are larger under cloudy 

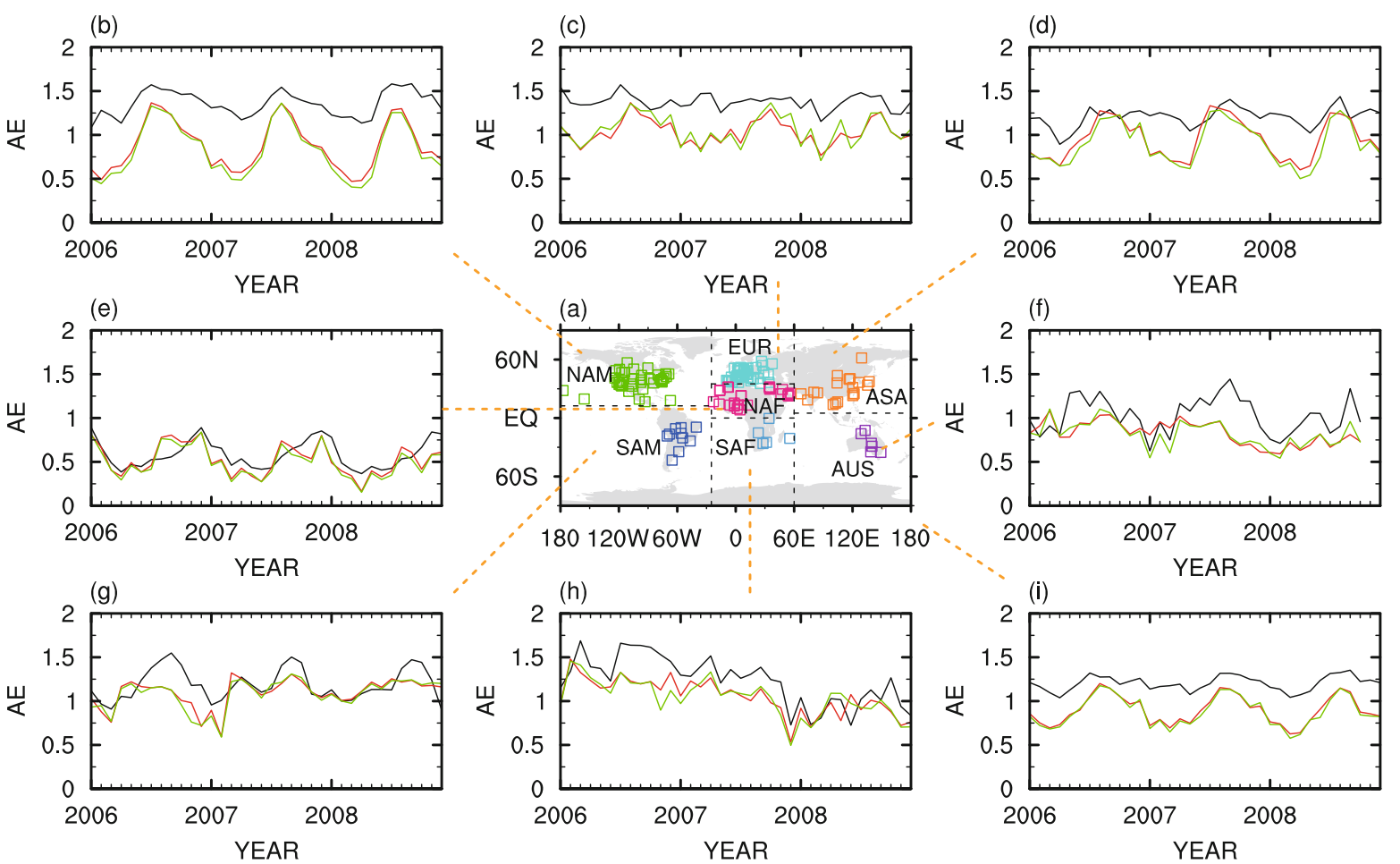

Fig. 8. As in Fig. 7 but for AEs (440/870 nm).
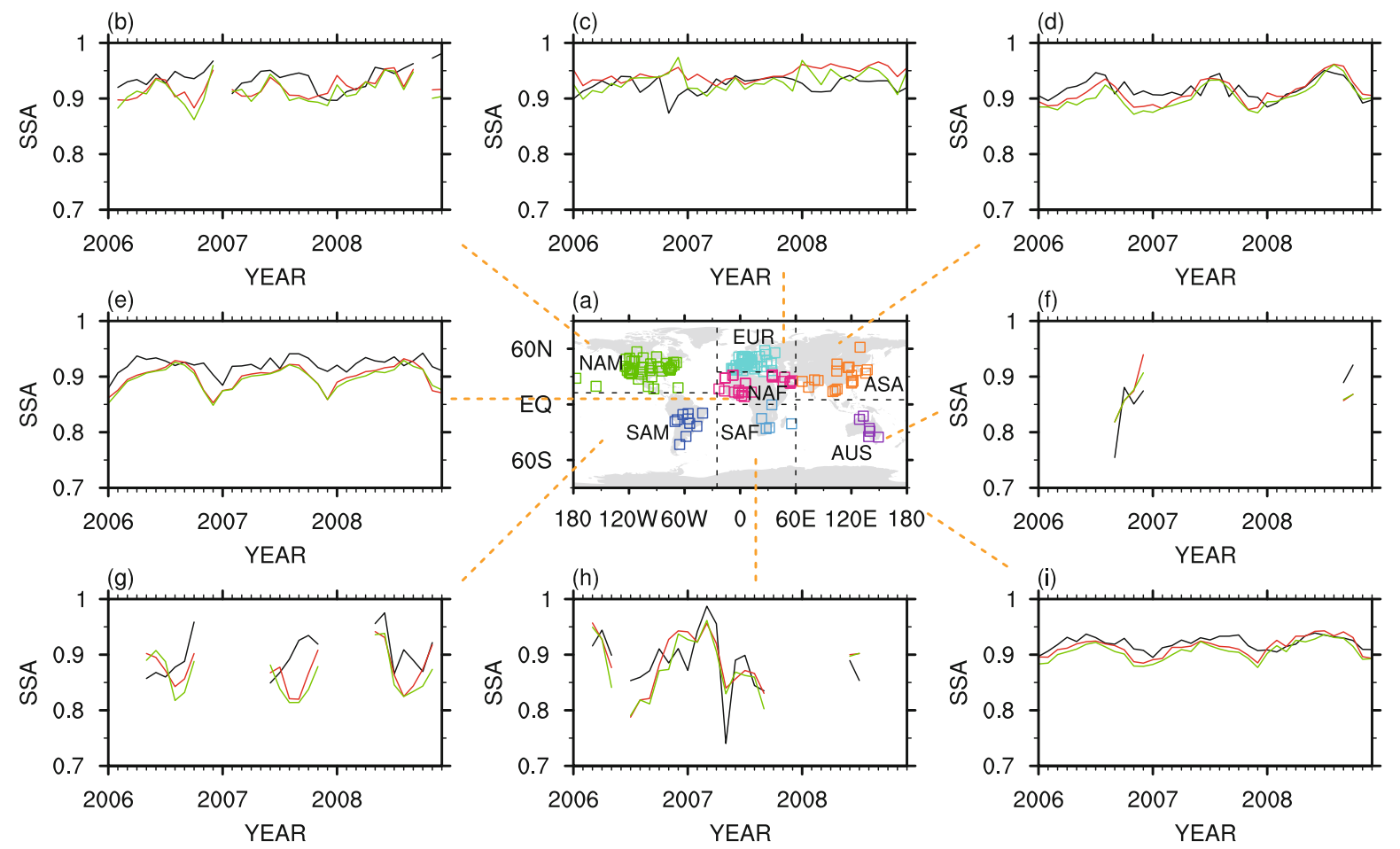

Fig. 9. As in Fig. 7 but for SSA at $550 \mathrm{~nm}$.

conditions because of hygroscopic growth, so the all-sky AE values are lower. In contrast, the low AEs indicate the aerosol composition is mostly dust. This hydrophobic aerosol is not influenced much by the cloud, but the extinction coef- ficients of hydrophilic aerosols in clear-sky conditions are lower than in all-sky conditions, and this induces the lower all-sky AEs. The clear-sky SSAs are mostly lower than the all-sky SSAs, especially over those regions dominated by 
Table 5. Summary of the statistical parameters for the comparisons shown in Fig. 8.

\begin{tabular}{|c|c|c|c|c|c|c|c|}
\hline \multirow[b]{2}{*}{ Region } & \multirow[b]{2}{*}{ MODIS Mean } & \multicolumn{2}{|c|}{$R$} & \multicolumn{2}{|c|}{ Bias } & \multicolumn{2}{|c|}{ Model Skill } \\
\hline & & All-sky & Clear-sky & All-sky & Clear-sky & All-sky & Clear-sky \\
\hline NAM & 1.356 & 0.894 & 0.902 & -0.484 & -0.534 & 0.640 & 0.587 \\
\hline SAM & 1.190 & 0.473 & 0.474 & -0.093 & -0.108 & 0.726 & 0.734 \\
\hline EUR & 1.378 & 0.450 & 0.403 & -0.341 & -0.318 & 0.585 & 0.471 \\
\hline NAF & 0.589 & 0.701 & 0.735 & -0.062 & -0.090 & 0.841 & 0.859 \\
\hline SAF & 1.235 & 0.808 & 0.776 & -0.183 & -0.193 & 0.830 & 0.832 \\
\hline ASA & 1.206 & 0.577 & 0.637 & -0.255 & -0.304 & 0.495 & 0.496 \\
\hline AUS & 1.030 & 0.337 & 0.624 & -0.203 & -0.212 & 0.562 & 0.721 \\
\hline All & 1.204 & 0.875 & 0.864 & -0.305 & -0.322 & 0.627 & 0.590 \\
\hline
\end{tabular}

Table 6. Summary of the statistical parameters for the comparisons as shown in Fig. 9.

\begin{tabular}{|c|c|c|c|c|c|c|c|}
\hline \multirow[b]{2}{*}{ Region } & \multirow[b]{2}{*}{ MODIS Mean } & \multicolumn{2}{|c|}{$R$} & \multicolumn{2}{|c|}{ Bias } & \multicolumn{2}{|c|}{ Model Skill } \\
\hline & & All-sky & Clear-sky & All-sky & Clear-sky & All-sky & Clear-sky \\
\hline NAM & 0.937 & 0.245 & 0.312 & -0.019 & -0.025 & 0.614 & 0.653 \\
\hline SAM & 0.899 & 0.392 & 0.329 & -0.024 & -0.037 & 0.694 & 0.664 \\
\hline EUR & 0.924 & -0.189 & -0.037 & 0.019 & 0.007 & 0.389 & 0.470 \\
\hline NAF & 0.921 & 0.672 & 0.704 & -0.021 & -0.024 & 0.711 & 0.744 \\
\hline SAF & 0.891 & 0.656 & 0.695 & -0.000 & -0.009 & 0.817 & 0.842 \\
\hline ASA & 0.917 & 0.678 & 0.666 & -0.005 & -0.014 & 0.795 & 0.787 \\
\hline AUS & 0.876 & 0.427 & 0.597 & 0.005 & 0.002 & 0.662 & 0.636 \\
\hline All & 0.921 & 0.715 & 0.760 & -0.007 & -0.015 & 0.773 & 0.801 \\
\hline
\end{tabular}

sulfate aerosol, further indicating the lesser contribution of the non-absorption sulfate aerosol under clear-sky conditions. Figures 10d-i show comparisons between the modeled and AERONET-retrieved values, and the statistics that reveal the comparison between the model simulations and AERONET observations are summarized in a Taylor diagram (Taylor, 2001) (not shown for brevity). Comparing the modeled allsky AOTs with the AERONET retrievals, we find that they are generally in reasonable agreement with $R$ ranging from 0.419 in the EUR region to 0.921 in the AUS region, and the modeled standard deviations are generally lower than those of the retrievals. The latter could be induced by the coarse model resolution. The modeled value represents an average over a GCM grid box of about $220 \times 220 \mathrm{~km}^{2}$, which is little affected by the local aerosol sources. The observations of AERONET may be influenced by the local aerosol sources, such as over the urban sites. This is further verified by the general underestimation of high AOTs $(>0.5)$. Using the clear-sky AOTs, the $R$ and the root-mean-square error are generally improved, except over the ASA region. Comparing the modeled all-sky AEs with the AERONET retrievals, we find that the variations of the AE values are captured well with $R>0.6$ except over the NAF and AUS regions, while the model tends to underestimate the AE values over the NAM, EUR, and ASA regions. We consider two possible explanations for the AE underestimation here. One is that the removal processes of dust aerosols may be underestimated in our model, and this induces more suspended dust over the outflow regions. The lifetime or residence time of dust is 8.2 days in our model, which is about twice that of the AeroCom mean (4.2 days). The other possible explanation is that our model may also have less scavenging for large dust particles, and this induces an incorrect dust size distribution over the outflow regions. SPRINTARS uses a single-moment scheme to track only the dust mass in 10 bins, as compared to the two-moment dust model that also includes the size distribution (Adams and Seinfeld, 2002; Peng et al., 2012). Although the underestimation of AE is further enlarged when using the clear-sky results, especially over the NAM and ASA regions, $R$ is generally improved. The $R$ values between modeled allsky SSAs and retrievals are generally low $(<0.3)$ and the modeled standard deviations are generally lower than those of the retrievals. The clear-sky values can slightly improve the value of $R$.

\section{Conclusion}

The global spatial and temporal distributions of the major aerosol optical properties, i.e., AOT, AE, and SSA, are simulated using a new aerosol-coupled non-hydrostatic icosahedral atmospheric model from 2006 to 2008. The 3-year global mean AOT, AE and SSA at $550 \mathrm{~nm}$ are estimated at $0.123,0.657$ and 0.944 , respectively, with soil dust having the largest AOT (0.035), followed by sulfate aerosol (0.032), carbonaceous aerosol (0.030), and sea salt (0.026). For all the aerosol species, the mean AOTs are within the ranges of the AeroCom results.

To include the effect of cloud on the aerosol model evaluation, the model results are separated to all-sky and clear-sky results. The simulated spatial distribution of all-sky AOTs can generally reproduce the MODIS retrievals. The transpacific transport of the aerosol plume and the seasonal varia- 
(a)

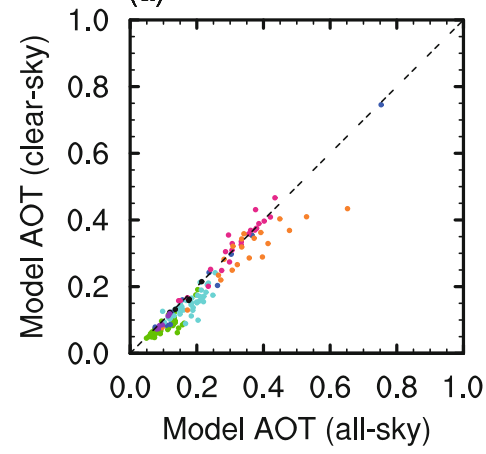

(d)

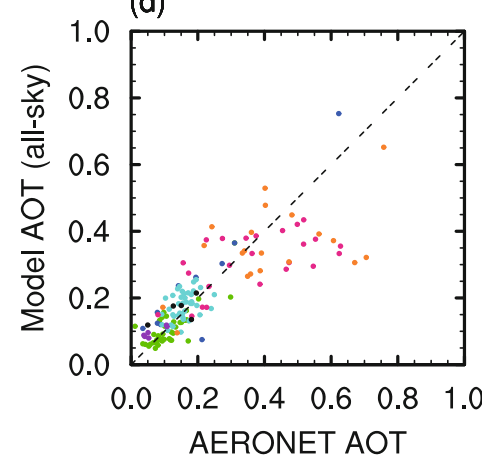

(g)

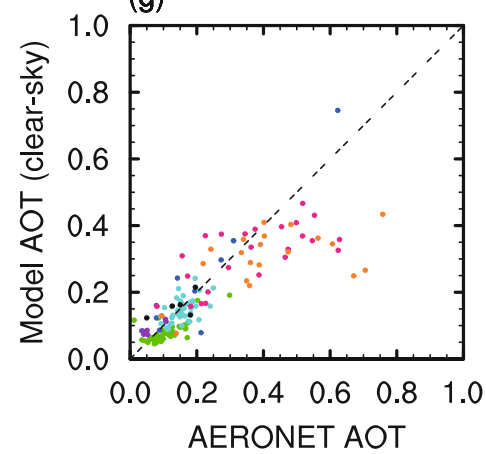

(b)

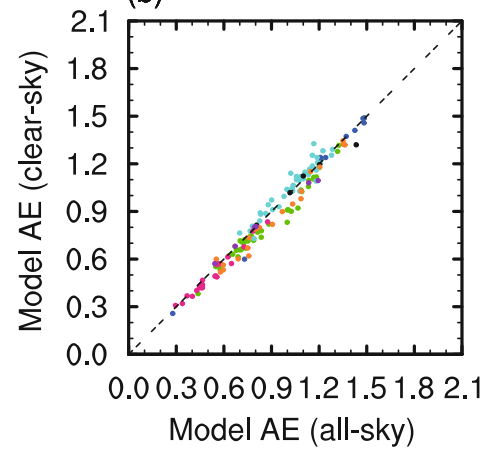

(e)

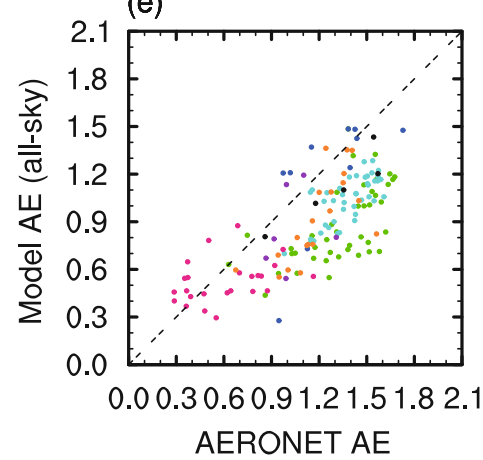

(h)

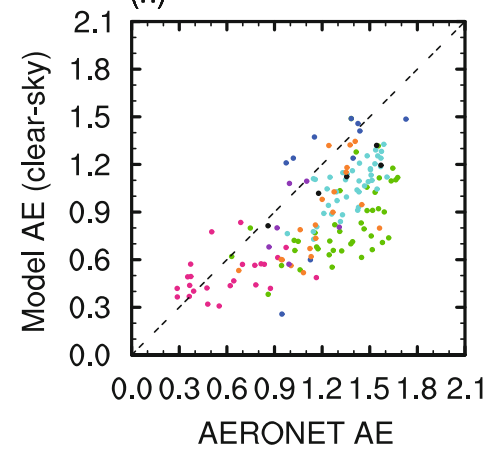

(c)
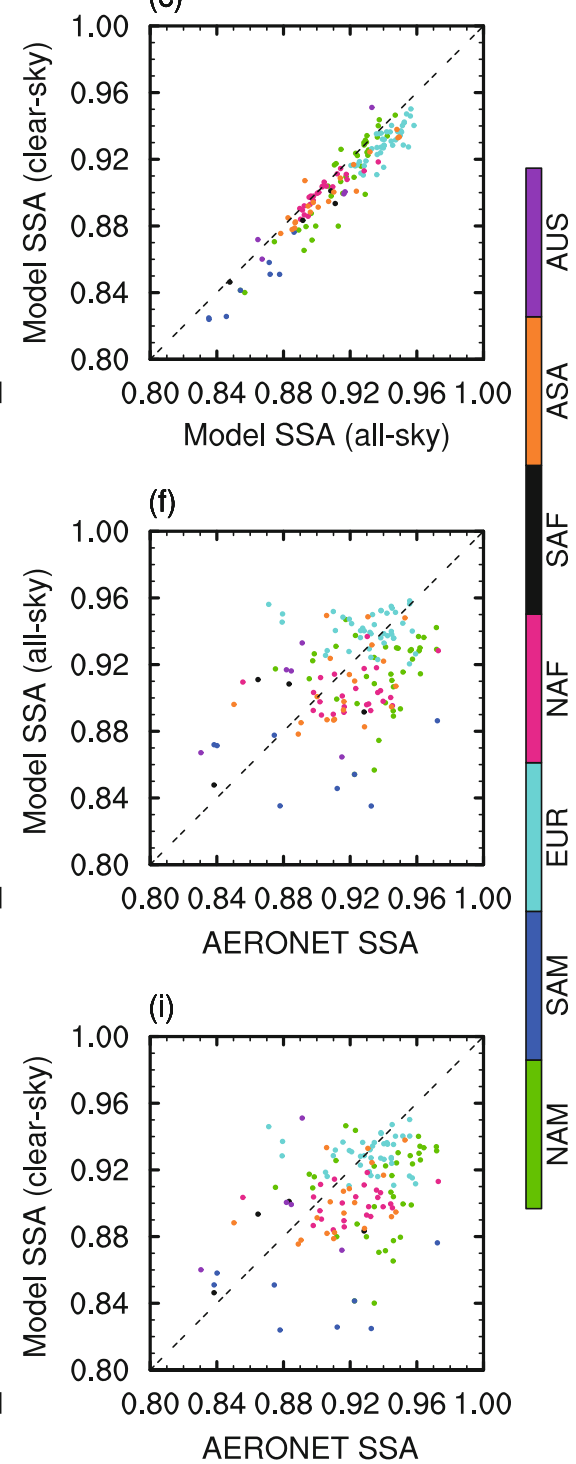

Fig. 10. Inter-comparison of the modeled all-sky, clear-sky and AERONET-retrieved 3-year mean AOTs at 550 nm (left column), AEs (440/870 nm) (middle column), and SSAs at $550 \mathrm{~nm}$ (right column) at all the available AERONET sites in this study. Each point represents the site-specific 3-year mean results, and points are colored according to the seven world regions.

tion of AOTs are in reasonable agreement with the retrievals. Although the clear-sky results show larger bias to the observations, they are in better agreement with the retrievals with higher $R$ and model skill. The differences between the modeled AOTs and observations are larger under the higher cloud fraction conditions. Compared with the ground-based AERONET observations, the modeled clear-sky AOT, AE, and SSA are generally in better agreement with observations than the all-sky results, based on $R$. The clear-sky AOTs and SSAs are generally lower than the all-sky results, especially over those regions where aerosols are mostly from pollution sources, because the non-absorbing sulfate is mostly formed in cloud and the hygroscopic growth is more effective in higher humidity regions near the cloud. The modeled clear-sky AEs could be either larger or smaller than the all-sky AEs, depending on the aerosol chemical composition. Although larger differences between all-sky and clear-sky results are found over the pollution regions, the differences are smaller than the aerosol seasonal and spatial variations.

The modeled AEs are exclusively lower than the AERONET retrievals in the NAM, EUR, and ASA regions, highlighting the uncertainties of the aerosol processes in our model. An investigation of the model's uncertainties using updated emission inventories and observations (Levy et al., 2013) will provide multi-dimensional diagnostics of the model's shortcomings, as well as possible remedies. Recently, the aerosol assimilation system of NICAM+SPRINTARS has been developed to overcome some of the uncertainties involved in the aerosol processes (Dai et al., 2013; Dai et al., 2014b), helping to improve the 
simulation of aerosol optical properties over East Asia.

Acknowledgements. SHI Guangyu and DAI Tie are supported by projects from National Natural Science Funds of China (Grant Nos. 41130104, and 41475031), Open Research Program of Key Laboratory for Aerosol-Cloud-Precipitation of China Meteorological Administration from Nanjing University of Information Science and Technology (Grant No. KDW1302), the Public Meteorology Special Foundation of MOST (Grant No. GYHY201406023), the National Key Basic Research and Development Program (973 Program, 2011CB403401), and Teruyuki NAKAJIMA is supported by projects from JAXA/EarthCARE, MEXT/VL for Climate System Diagnostics, the MOE/Global Environment Research Fund A-1101, NIES/GOSAT, NIES/CGER, MEXT/RECCA/SALSA, and the S-12 of the MOE.

Open Access. This article is distributed under the terms of the Creative Commons Attribution License which permits any use, distribution, and reproduction in any medium, provided the original author(s) and the source are credited.

\section{REFERENCES}

Acker, J. G., and G. Leptoukh, 2007: Online analysis enhances use of NASA Earth science data. Eos, Trans. Amer. Geophys. Union, 88(2), 14-17.

Ackerman, S. A., K. I. Strabala, W. P. Menzel, R. A. Frey, C. C. Moeller, and L. E. Gumley, 1998: Discriminating clear sky from clouds with MODIS. J. Geophys. Res., 103(D24), 32141-32157.

Adams, P. J., and J. H. Seinfeld, 2002: Predicting global aerosol size distributions in general circulation models. J. Geophys. Res.: Atmos., 107(D19), AAC 4-1-AAC 4-23.

Arakawa, A., and W. H. Schubert, 1974: Interaction of a cumulus cloud ensemble with the Large-Scale environment, Part I. $J$. Atmos. Sci., 31(3), 674-701.

Barnes, W. L., T. S. Pagano, and V. V. Salomonson, 1998: Prelaunch characteristics of the Moderate Resolution Imaging Spectroradiometer (MODIS) on EOS-AM1. IEEE Trans. Geosci. Remote Sens., 36(4), 1088-1100.

Bi, J. R., J. P. Huang, Q. Fu, X. Wang, J. S. Shi, W. Zhang, H. W. Huang, and B. D. Zhang, 2011: Toward characterization of the aerosol optical properties over Loess Plateau of Northwestern China. Journal of Quantitative Spectroscopy and Radiative Transfer, 112(2), 346-360.

Chand, D., and Coauthors, 2012: Aerosol optical depth increase in partly cloudy conditions. J. Geophys. Res.: Atmos., 117(D17), D17207, doi: 10.1029/2012JD017894.

Chin, M., and Coauthors, 2002: Tropospheric aerosol optical thickness from the GOCART model and comparisons with satellite and sun photometer measurements. J. Atmos. Sci., 59(3), 461-483.

Chin, M., T. Diehl, O. Dubovik, T. F. Eck, B. N. Holben, A. Sinyuk, and D. G. Streets. 2009: Light absorption by pollution, dust, and biomass burning aerosols: A global model study and evaluation with AERONET measurements. Ann. Geophys., 27, 3439-3464.

Chin, M., and Coauthors, 2014: Multi-decadal aerosol variations from 1980 to 2009: A perspective from observations and a global model. Atmospheric Chemistry and Physics, 14(7), $3657-3690$

Chung, C. E., V. Ramanathan, and D. Decremer, 2012: Observationally constrained estimates of carbonaceous aerosol radiative forcing. Proceedings of the National Academy of Sciences of the United States of America, 109(29), 11624-11629.

Colarco, P., A. da Silva, M. Chin, and T. Diehl, 2010: Online simulations of global aerosol distributions in the NASA GEOS-4 model and comparisons to satellite and ground-based aerosol optical depth. J. Geophy. Res.: Atmos., 115(D14), D14207, doi: 10.1029/2009JD012820.

Cooke, W. F., and J. J. N. Wilson, 1996: A global black carbon aerosol model. J. Geophys. Res., 101(D14), 19 395-19 409.

Dai, T., N. A. J. Schutgens, and T. Nakajima, 2013: Applying a local Ensemble transform Kalman filter assimilation system to the NICAM-SPRINTARS model. AIP Conference Proceedings, 1531(1), 744-747.

Dai, T., D. Goto, N. A. J. Schutgens, X. Dong, G. Shi, and T. Nakajima, 2014a: Simulated aerosol key optical properties over global scale using an aerosol transport model coupled with a new type of dynamic core. Atmos. Enviro., 82, 71-82.

Dai, T., N. A. J. Schutgens, D. Goto, G. Shi, and T. Nakajima, 2014b: Improvement of aerosol optical properties modeling over Eastern Asia with MODIS AOD assimilation in a global non-hydrostatic icosahedral aerosol transport model. Environmental Pollution, 195, 319-329.

Diehl, T., A. Heil, M. Chin, X. Pan, D. Streets, M. Schultz, and S. Kinne, 2012: Anthropogenic, biomass burning, and volcanic emissions of black carbon, organic carbon, and $\mathrm{SO}_{2}$ from 1980 to 2010 for hindcast model experiments. Atmospheric Chemistry and Physics Discussions, 12(9), 24 895-24 954.

Dubovik, O., and M. D. King, 2000: A flexible inversion algorithm for retrieval of aerosol optical properties from Sun and sky radiance measurements. J. Geophys. Res., 105(D16), $20673-20696$.

Dubovik, O., A. Smirnov, B. N. Holben, M. D. King, Y. J. Kaufman, T. F. Eck, and I. Slutsker, 2000: Accuracy assessments of aerosol optical properties retrieved from Aerosol Robotic Network (AERONET) Sun and sky radiance measurements. J. Geophys. Res., 105(D8), 9791-9806.

Geleyn, J. F., and A. Hollingsworth, 1979: An economical analytical method for the computation of the interaction between scattering and line absorption of radiation. Beitr. Phys. Atmos., 52, 1-16.

Goto, D., T. Nakajima, T. Takemura, and K. Sudo, 2011a: A study of uncertainties in the sulfate distribution and its radiative forcing associated with sulfur chemistry in a global aerosol model. Atmos. Chem. Phys., 11(21), 10 889-10910.

Goto, D., N. A. J. Schutgens, T. Nakajima, and T. Takemura, 2011b: Sensitivity of aerosol to assumed optical properties over Asia using a global aerosol model and AERONET. Geophys. Res. Lett., 38(17), L17810, doi: 10.1029/2011GL 048675.

Goto, D., S. Kanazawa, T. Nakajima, and T. Takemura, 2012: Evaluation of a relationship between aerosols and surface downward shortwave flux through an integrative analysis of modeling and observation. Atmos. Environ., 49, 294-301.

Holben, B., and Coauthors, 1998: AERONET-A federated instrument network and data archive for aerosol characterization. Remote Sens. Environ., 66(1), 1-16.

Kampa, M., and E. Castanas, 2008: Human health effects of air pollution. Environmental Pollution, 151(2), 362-367. 
Kaufman, Y. J., D. Tanré L. A. Remer, E. F. Vermote, A. Chu, and B. N. Holben, 1997: Operational remote sensing of tropospheric aerosol over land from EOS moderate resolution imaging spectroradiometer. J. Geophys. Res.: Atmos., 102 (D14), 17 051-17 067.

King, M. D., Y. J. Kaufman, W. P. Menzel, and D. Tanre, 1992: Remote sensing of cloud, aerosol, and water vapor properties from the moderate resolution imaging spectrometer (MODIS). IEEE Trans. Geosci. Remote Sens., 30(1), 2-27.

King, M. D., and Coauthors, 2003: Cloud and aerosol properties, precipitable water, and profiles of temperature and water vapor from MODIS. IEEE Trans. Geosci. Remote Sens., 41(2), $442-458$.

Kinne, S., and Coauthors, 2003: Monthly averages of aerosol properties: A global comparison among models, satellite data, and AERONET ground data. J. Geophys. Res.: Atmos., 108(D20), 4634, doi: 10.1029/2001JD001253.

Kinne, S., and Coauthors, 2006: An AeroCom initial assessmentoptical properties in aerosol component modules of global models. Atmos. Chem. Phys., 6(7), 1815-1834.

Le Trent, H., and Z.-X. Li, 1991: Sensitivity of an atmospheric general circulation model to prescribed SST changes: Feedback effects associated with the simulation of cloud optical properties. Climate Dyn., 5(3), 175-187.

Lee, L. A., K. J. Pringle, C. L. Reddington, G. W. Mann, P. Stier, D. V. Spracklen, J. R. Pierce, and K. S. Carslaw, 2013: The magnitude and causes of uncertainty in global model simulations of cloud condensation nuclei. Atmospheric Chemistry and Physics, 13(17), 8879-8914.

Lee, Y. H., and P. J. Adams, 2010: Evaluation of aerosol distributions in the GISS-TOMAS global aerosol microphysics model with remote sensing observations. Atmospheric Chemistry and Physics, 10(5), 2129-2214.

Levy, R. C., S. Mattoo, L. A. Munchak, L. A. Remer, A. M. Sayer, F. Patadia, and N. C. Hsu, 2013: The Collection 6 MODIS aerosol products over land and ocean. Atmospheric Measurement Techniques, 6(11), 2989-3034.

Logan, T., B. Xi, X. Dong, R. Obrecht, Z. Li, and M. Cribb, 2010: A study of Asian dust plumes using satellite, surface, and aircraft measurements during the INTEX-B field experiment. $J$. Geophys. Res., 115, D00K25, doi: 10.1029/2010JD014134.

Logan, T., B. Xi, X. Dong, Z. Li, and M. Cribb, 2013: Classification and investigation of Asian aerosol absorptive properties. Atmospheric Chemistry and Physics, 13(4), 2253-2265.

Lohmann, U., and Coauthors, 2010: Total aerosol effect: radiative forcing or radiative flux perturbation? Atmospheric Chemistry and Physics, 10(7), 3235-3246.

Mann, G. W., and Coauthors, 2014: Intercomparison and evaluation of global aerosol microphysical properties among AeroCom models of a range of complexity. Atmospheric Chemistry and Physics, 14(9), 4679-4713.

Martins, J. V., D. Tanré L. Remer, Y. Kaufman, S. Mattoo, and R. Levy, 2002: MODIS Cloud screening for remote sensing of aerosols over oceans using spatial variability. Geophys. Res. Lett., 29(12), MOD4-1-MOD4-4.

Mellor, G. L., and T. Yamada, 1974: A hierarchy of turbulence closure models for planetary boundary layers. J. Atmos. Sci., 31(7), 1791-1806.

Miura, H., M. Satoh, T. Nasuno, A. T. Noda, and K. Oouchi, 2007: A Madden-Julian oscillation event realistically simulated by a global Cloud-Resolving model. Science, 318(5857), 17631765 .
Nakajima, T., M. Tsukamoto, Y. Tsushima, A. Numaguti, and T. Kimura, 2000: Modeling of the radiative process in an atmospheric general circulation model. Appl. Opt., 39(27), 48694878.

Niwa, Y., and Coauthors, 2011a: Three-dimensional variations of atmospheric $\mathrm{CO}_{2}$ : aircraft measurements and multi-transport model simulations. Atmospheric Chemistry and Physics, 11(24), 13359-13375.

Niwa, Y., H. Tomita, M. Satoh, and R. Imasu, 2011b: A threedimensional icosahedral grid advection scheme preserving monotonicity and consistency with continuity for atmospheric tracer transport. J. Meteor. Soc. Japan, 89(3), 255-268.

Peng, Y., K. von Salzen, and J. Li, 2012: Simulation of mineral dust aerosol with Piecewise Log-normal Approximation (PLA) in CanAM4-PAM. Atmospheric Chemistry and Physics, 12(15), 6891-6914.

Prados, A. I., S. Kondragunta, P. Ciren, and K. R. Knapp, 2007: GOES Aerosol/Smoke Product (GASP) over North America: Comparisons to AERONET and MODIS observations. J. Geophys. Res.: Atmos., 112(D15), D15201, doi: 10.1029/2006JD007968.

Remer, L. A., and Y. J. Kaufman, 2006: Aerosol direct radiative effect at the top of the atmosphere over cloud free ocean derived from four years of MODIS data. Atmospheric Chemistry and Physics, 6(1), 237-253.

Remer, L. A., and Coauthors, 2005: The MODIS aerosol algorithm, products, and validation. J. Atmos. Sci., 62(4), 947973.

Ridley, D. A., C. L. Heald, and B. Ford, 2012: North African dust export and deposition: A satellite and model perspective. J. Geophys. Res., 117(D2), D02202, doi: 10.1029/2011JD 016794.

Salomonson, V. V., W. L. Barnes, P. W. Maymon, H. E. Montgomery, and H. Ostrow, 1989: MODIS: Advanced facility instrument for studies of the Earth as a system. IEEE Trans. Geosci. Remote Sens., 27(2), 145-153.

Satoh, M., T. Matsuno, H. Tomita, H. Miura, T. Nasuno, and S. Iga, 2008: Nonhydrostatic icosahedral atmospheric model (NICAM) for global cloud resolving simulations. J. Comput. Phys., 227(7), 3486-3514.

Seiki, T., and T. Nakajima, 2014: Aerosol effects of the condensation process on a convective cloud simulation. J. Atmos. Sci., 71(2), 833-853.

Seiki, T., M. Satoh, H. Tomita, and T. Nakajima, 2014: Simultaneous evaluation of ice cloud microphysics and nonsphericity of the cloud optical properties using hydrometeor video sonde and radiometer sonde in situ observations. J. Geophys. Res.: Atmos., 119(11), 6681-6701.

Sekiguchi, M., and T. Nakajima, 2008: A k-distribution-based radiation code and its computational optimization for an atmospheric general circulation model. Journal of Quantitative Spectroscopy and Radiative Transfer, 109(17-18), 2779 2793.

Su, L., and O. B. Toon, 2011: Saharan and Asian dust: Similarities and differences determined by CALIPSO, AERONET, and a coupled climate-aerosol microphysical model. Atmos. Chem. Phys., 11(7), 3263-3280.

Sudo, K., M. Takahashi, J.-i. Kurokawa, and H. Akimoto, 2002: CHASER: A global chemical model of the troposphere 1. Model description. J. Geophys. Res., 107(D17), ACH 7-1ACH 7-20.

Suzuki, K., T. Nakajima, M. Satoh, H. Tomita, T. Takemura, T. Y. 
Nakajima, and G. L. Stephens, 2008: Global cloud-systemresolving simulation of aerosol effect on warm clouds. Geophys. Res. Lett., 35(19), L19817, doi: 10.1029/2008GL 035449.

Takata, K., S. Emori, and T. Watanabe, 2003: Development of the minimal advanced treatments of surface interaction and runoff. Global and Planetary Change, 38(1-2), 209-222.

Takemura, T., H. Okamoto, Y. Maruyama, A. Numaguti, A. Higurashi, and T. Nakajima, 2000: Global three-dimensional simulation of aerosol optical thickness distribution of various origins. J. Geophys. Res., 105(D14), 17 853-17 873.

Takemura, T., T. Nakajima, O. Dubovik, B. N. Holben, and S. Kinne, 2002a: Single-scattering albedo and radiative forcing of various aerosol species with a global Three-Dimensional model. J. Climate, 15(4), 333-352.

Takemura, T., I. Uno, T. Nakajima, A. Higurashi, and I. Sano, 2002b: Modeling study of long-range transport of Asian dust and anthropogenic aerosols from East Asia. Geophys. Res. Lett., 29(24), 11-1-11-4.

Takemura, T., M. Egashira, K. Matsuzawa, H. Ichijo, R. O'Ishi, and A. Abe-Ouchi, 2009: A simulation of the global distribution and radiative forcing of soil dust aerosols at the Last Glacial Maximum. Atmospheric Chemistry and Physics, 9(9), 3061-3073.

Tanré, D., Y. J. Kaufman, M. Herman, and S. Mattoo, 1997: Remote sensing of aerosol properties over oceans using the MODIS/EOS spectral radiances. J. Geophys. Res., 102(D14), $16971-16988$.

Taylor, K. E., 2001: Summarizing multiple aspects of model per- formance in a single diagram. J. Geophys. Res., 106(D7), 7183-7192.

Textor, C., and Coauthors, 2006: Analysis and quantification of the diversities of aerosol life cycles within AeroCom. Atmos. Chem. Phys., 6(7), 1777-1813.

Textor, C., and Coauthors, 2007: The effect of harmonized emissions on aerosol properties in global models-an AeroCom experiment. Atmospheric Chemistry and Physics, 7(17), 44894501.

Tomita, H., 2008: New microphysical schemes with five and six categories by diagnostic generation of cloud ice. J. Meteor. Soc. Japan Ser. II, 86A, 121-142.

Twomey, S., 1974: Pollution and the planetary albedo. Atmos. Environ., 8(12), 1251-1256.

Wang, X., J. Huang, M. Ji, and K. Higuchi, 2008: Variability of East Asia dust events and their long-term trend. Atmos. Environ., 42(13), 3156-3165.

Yang, Y. Q., Q. Hou, C. H. Zhou, H. L. Liu, Y. Q. Wang, and T. Niu, 2008: Sand/dust storm processes in Northeast Asia and associated large-scale circulations. Atmospheric Chemistry and Physics, 8(1), 25-33.

Zhang, H., and Coauthors, 2012a: Simulation of direct radiative forcing of aerosols and their effects on East Asian climate using an interactive AGCM-aerosol coupled system. Climate Dyn., 38(7-8), 1675-1693.

Zhang, K., and Coauthors, 2012b: The global aerosol-climate model ECHAM-HAM, version 2: Sensitivity to improvements in process representations. Atmospheric Chemistry and Physics, 12(19), 8911-8949. 